\title{
GCD10, a translational repressor of GCN4, is the RNA-binding subunit of eukaryotic translation initiation factor-3
}

\author{
Minerva T. Garcia-Barrio, ${ }^{1,2,4}$ Tatjana Naranda, ${ }^{3,4}$ Carlos R. Vazquez de Aldana, ${ }^{2}$ Rafael Cuesta, ${ }^{1}$ \\ Alan G. Hinnebusch, ${ }^{2}$ John W.B. Hershey, ${ }^{3}$ and Mercedes Tamame ${ }^{1,5}$ \\ ${ }^{1}$ Instituto de Microbiologia-Bioquimica, Consejo Superior de Investigaciones Cientificas/Universidad de Salamanca, Facultad \\ de Biologia, 37008 Salamanca, Spain; ${ }^{2}$ Section on Molecular Genetics of Lower Eukaryotes, Laboratory of Molecular \\ Genetics, National Institute of Child Health and Human Development, Bethesda, Maryland 20892 USA; ${ }^{3}$ Department \\ of Biological Chemistry, School of Medicine, University of California, Davis, California 95616 USA
}

GCN4 mRNA is translated by a reinitiation mechanism involving four short upstream open reading frames (uORFs) in its leader sequence. Decreasing the activity of eukaryotic initiation factor-2 (eIF-2) by phosphorylation inhibits general translation in yeast but stimulates GCN4 expression by allowing ribosomes to scan past the uORFs and reinitiate at GCN4 instead. GCD10 was first identified genetically as a translational repressor of GCN4. We show here that GCD10 is an essential protein of $54.6 \mathrm{kD}$ that is required in vivo for the initiation of total protein synthesis. GCD10 binds RNA in vitro and we present strong biochemical evidence that it is identical to the RNA-binding subunit of yeast initiation factor-3 (eIF-3). eIF-3 is a multisubunit complex that stimulates translation initiation in vitro at several different steps. We suggest that gcd10 mutations decrease the ability of eIF-3 to stimulate binding of eIF-2/GTP/Met-tRNA $A_{i}^{\text {Met }}$ ternary complexes to small ribosomal subunits in vivo. This would explain why mutations in eIF-3 mimic eIF-2 $\alpha$ phosphorylation in allowing ribosomes to bypass the uORFs and reinitiate at GCN4. Our results indicate that GCN4 expression provides a sensitive in vivo assay for the function of eIF-3 in initiation complex formation.

[Key Words: GCN4 expression; translation initiation factor; yeast initiation factor; upstream open reading frames; eIF-3; protein synthesis]

Received March 28, 1995; revised version accepted June 6, 1995.

The expression of $>40$ genes encoding amino acid biosynthetic enzymes in 11 different pathways is coregulated in Saccharomyces cerevisiae by the transcriptional activator GCN4 (the general amino acid control). GCN4 protein accumulates in response to starvation for any single amino acid, or for purines (Rolfes and Hinnebusch 1993), and stimulates transcription of the biosynthetic genes under its control (for review, see Hinnebusch 1992). Regulation of GCN4 expression by amino acid availability occurs at the translational level and depends on four short upstream open reading frames (uORFs) in the leader of its mRNA. These uORFs restrict the flow of scanning ribosomes to the GCN4 initiation codon when amino acids are abundant. In contrast, under starvation conditions, many ribosomes that translate uORF1 and resume scanning ignore the start codons at uORFs 2-4 and reinitiate at GCN4 instead (for review, see Hinnebusch 1992, 1994).

GCN2 is a protein kinase that stimulates translation of GCN4 mRNA by phosphorylating the $\alpha$-subunit of

\footnotetext{
${ }^{4}$ These authors contributed equally to this work.

${ }^{5}$ Corresponding author.
}

translation initiation factor-2 (eIF-2 $\alpha$ ) on serine 51 (Dever et al. 1992). In mammalian cells, this phosphorylation event decreases the activity of the guanine nucleotide exchange factor for eIF-2, known as eIF-2B, thereby reducing the level of the GTP-bound form of eIF-2. Because only eIF-2.GTP can deliver initiator methionyltRNA (Met-tRNA $\mathrm{i}_{\mathrm{i}}^{\mathrm{Met}}$ ) to the $43 \mathrm{~S}$ preinitiation complex, phosphorylation of eIF-2 elicits a general inhibition of translation initiation (for review, see Hershey 1991). By analogy with these findings, it was proposed that phosphorylation of eIF- $2 \alpha$ by GCN2 in yeast would decrease the concentration of eIF-2/GTP/Met-tRNA ${ }_{i}^{\text {Met }}$ ternary complexes. This reduction in ternary complex levels would allow ribosomes to scan past uORFs 2-4 and reinitiate farther downstream at GCN4 (Dever et al. 1992)

This hypothesis is supported by the finding that reduced-function mutations in each of the four essential subunits of eIF-2B (encoded by GCD1, GCD2, GCD6, and GCD7), and in each of the three subunits of eIF-2 (encoded by SUI2, SUI3, and GCD11) lead to high levels of GCN4 translation in the absence of GCN2 or nutrient starvation (Hannig et al. 1992; Hinnebusch 1992, 1994). Presumably, these nonlethal mutations substitute for 
the inhibitory effects of eIF- $2 \alpha$ phosphorylation in reducing the recycling of eIF- 2 catalyzed by eIF-2B. In addition, it has been possible to isolate amino acid substitutions in the GCN3 $(\alpha-), \operatorname{GCD} 7(\beta-)$, and GCD2 $(\delta-)$ subunits of eIF-2B that uncouple derepression of GCN4 translation from phosphorylation of eIF-2 by GCN2 /Vazquez de Aldana et al. 1993; Vazquez de Aldana and Hinnebusch 1994).

Reduced-function alleles of $G C D 1, G C D 2$, and GCD11 were isolated on the basis of restoring high-level expression of histidine biosynthetic enzymes subject to GCN4 control in mutant strains lacking the protein kinase GCN2 (Harashima and Hinnebusch 1986). The same selection yielded mutations in GCD10. In these gcd10 mutants, GCN4 expression is derepressed constitutively at the translational level and this derepression is completely dependent on the uORFs in the GCN4 mRNA leader (Harashima and Hinnebusch 1986; Mueller et al. 1987). Similar to other $g c d$ mutations, the mutations in GCD10 confer temperature-sensitive growth or unconditional slow growth on rich medium (Harashima and Hinnebusch 1986), suggesting that they impair an essential function in addition to altering GCN4 expression.

In this report we present the cloning and characterization of GCD10 and biochemical analysis of its protein product. Our results indicate that GCD10 encodes a 54.6-kD polypeptide that is essential for cell viability and contains a sequence related to the RNA-recognition motif (RRM) found in many RNA-binding proteins (Query et al. 1989; Birney et al. 1993). We present biochemical data indicating that GCD10 is associated with the translational machinery and is required for efficient initiation of total protein synthesis in vivo. In addition, we show that GCD10 binds RNA in vitro and provide strong evidence that it is identical to the RNA-binding subunit of yeast translation initiation factor-3 (eIF-3) (Naranda et al. 1994). eIF-3 is a multisubunit complex in both yeast and mammals that has been implicated by in vitro studies in several distinct reactions in translation initiation, including $80 \mathrm{~S}$ ribosome dissociation, binding of ternary complex to small ribosomal subunits, and mRNA binding to the ribosome (Benne and Hershey 1978; Trachsel and Staehelin 1979; Feinberg et al. 1982; Naranda et al. 1994; Danaie et al. 1995). Our results indicate that eIF-3 has a critical role in translational reinitiation on GCN4 mRNA. Given their effects on GCN4 expression, we propose that $g c d 10$ mutations decrease the ability of eIF-3 to facilitate binding of ternary complexes to small ribosomal subunits (Benne and Hershey 1978; Feinberg et al. 1982). This hypothesis provides a satisfying explanation for how defects in GCD10 can mimic the effects of eIF- $2 \alpha$ phosphorylation in derepressing the translation of GCN4 mRNA.

\section{Results}

\section{Isolation and characterization of the GCD10 gene}

Mutations in GCD10 were isolated as suppressors of the 3-aminotriazole (3-AT)-sensitive phenotype of a $\mathrm{gcn} 2$ -
101 gcn3-101 mutant (Harashima and Hinnebusch 1986). All $g c n$ mutations confer sensitivity to 3 -AT because they impair derepression of the general control system in response to histidine starvation imposed by this drug (Hinnebusch and Fink 1983a). gcd10 mutations restore derepression of the general control system and thus confer 3-AT-resistance $\left(3-\mathrm{AT}^{\mathrm{Y}}\right)$ in $g \mathrm{cn} 2$ and $g \mathrm{cn} 3$ mutants (Harashima and Hinnebusch 1986). We cloned wild-type GCD10 from a yeast genomic library on plasmid pMG1 (Fig. 1) by complementing the $\mathrm{AT}^{\mathrm{R}}$ and temperature-sensitive growth $\left(\mathrm{Tsm}^{-}\right)$phenotypes conferred by the gcd10-504 allele in the gcn2::LEU2 gcd10-504 strain $\mathrm{Hm} 47$. To prove that we had isolated authentic GCD10, we showed that a nonreplicating plasmid bearing a portion of the genomic insert from pMGl directed plasmid integration to a site closely linked to GCD10 in the yeast genome (see Materials and methods). GCD10 was mapped to the left arm of chromosome XIV between the RAS2/TOP2 region and the centromere by hybridizing a radiolabeled fragment from the pMGl insert to filters containing an ordered lambda library of yeast genomic clones (see Materials and methods). From tetrad analysis, we estimated that $G C D 10$ is $\sim 16 \mathrm{cM}$ from $R A S 2$ and TOP2 (see Materials and methods).

GCD10 was localized on the genomic insert in pMG1 by testing various subclones for complementation of the $\mathrm{AT}^{\mathrm{R}}$ and $\mathrm{Tsm}^{-}$phenotypes of $g c d 10-504$ in $\mathrm{Hm} 47$. Results summarized in Figure 1 initially localized GCD10 to the 3.45-kb HindIII fragment in pMG105. This fragment was sequenced on both strands and found to contain two large ORFs, neither of which was complete at the $3^{\prime}$ end. We determined which of these two ORFs encodes GCD10 by showing that the pMG107 subclone complements gcd10-504, whereas pMG101 does not (Fig. 1). Subsequently, we extended our sequence analysis to include the stop codon and presumed $3^{\prime}$-untranslated region of the complete GCD10 ORF contained in pMG107.

Inspection of the sequence revealed a small ORF beginning 112 bp upstream from the putative GCD10 start codon that overlaps the beginning of the GCD10 coding sequence by $26 \mathrm{bp}$ in a different reading frame. To investigate a possible role for this small ORF in GCD10 expression, we inserted 4 bp at a BamHI site located $54 \mathrm{bp}$ $3^{\prime}$ of the start codon of the upstream ORF and $58 \mathrm{bp} 5^{\prime}$ of the presumed GCD10 start site. This frameshift mutation terminates the short ORF prematurely at a stop codon that overlaps the GCD10 start codon. The frameshift construct fully complemented the $\mathrm{AT}^{\mathrm{R}} \mathrm{Tsm}^{-}$phenotypes of gcd10-504 (Fig. 1; pMG107-FSB), ruling out an important function for the upstream ORF. This last result also confirmed that the GCD10 ORF begins 3' of the $B a m H I$ site. Additional support for this interpretation was provided by the fact that a construct containing the GCD10 BamHI-Xhol fragment inserted 3' to the yeast GAL1 promoter complemented the lethality of a GCD10 deletion (see below).

The GCD10 allele in pMG105 complements gcd10504 even though it lacks the last 10 codons of the putative GCD10 ORF. In an effort to define more precisely the 3 ' end of the GCD10 functional unit, we constructed 


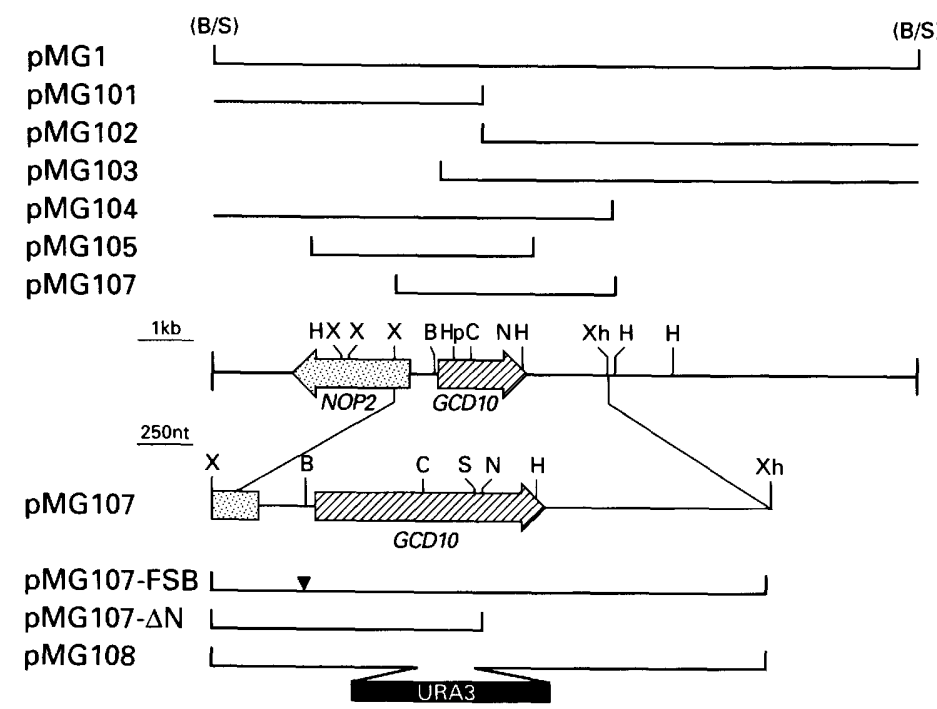

+ Figure 1. Functional analysis of the GCD10 gene.

+ In the center is shown a partial restriction map of

- the GCD10 region with arrows indicating the posi-

- tions of the two ORFs identified by sequencing,

- GCD10 and ORF2. The direction of transcription is

+ indicated by the polarity of the arrows. The se-

+ quence of ORF2 is identical to that of the NOP2

+ gene, identified recently in a sequence deposited in GenBank (accession no. X82656) by de Beus et al. (1994). The top line depicts the genomic DNA insert in pMGl; below that are depicted fragments present in subclones constructed from pMG1. The ability of each subclone to complement the pheno+ types of the gcd10-504 mutation is shown at right as + or - Below the map of the GCD10 region is + shown an enlargement of the fragment present in + pMG107, and beneath that are depicted derivatives - of pMG107. The triangle on the map of pMG107-

- FSB gives the position of a 4-bp insertion in the BamHI site 58 nucleotides $5^{\prime}$ of the GCD10 ATG start codon. In pMG108, a 491-bp internal fragment of GCD10 was replaced by the URA3 gene. Restriction enzyme sites: (B) BamHI; (H) HindIII; (X) XbaI; (C) ClaI; (N) NcoI; (Xh) XhoI; (Hp) HpaI, (there are two HpaI sites 28 bp apart); (S) SpeI; (B/S) BamHI-Sau3A junction.

pMG107- $\Delta \mathrm{N}$ lacking the last 97 codons of the predicted GCD10 ORF (Fig. 1). This construct failed to complement gcd10-504, indicating that the last 10-97 amino acids of GCD10 are required for its function. To investigate the size of the GCD10 transcription unit, we conducted blot-hybridization analysis of total yeast mRNA using a 1.34-kb EcoRI fragment containing most of the GCD10 coding sequence (positions -280 to +1063 ) as probe. This probe hybridized with a single transcript of $\sim 1.6 \mathrm{~kb}$ (data not shown), consistent with the predicted size of the GCD10 ORF of $1434 \mathrm{bp}$.

The GCD10 ORF predicts a protein of 478 amino acids with a molecular mass of 54,600 . Comparison of the deduced amino acid sequence of GCD10 with protein sequences in the GenBank, EMBL, and SWISS-PROT data bases revealed no high degree of sequence similarity to any known proteins. However, GCD10 does contain a segment of 65 amino acids (between residues 335 and 400 ) that is closely related to the consensus sequence for the structural core of the RRM found in many RNAbinding proteins (Fig. 2). The RRM is a degenerate consensus sequence containing a total of 7 highly conserved residues and 7 additional positions that are generally occupied by uncharged amino acids (Birney et al. 1993). The RRM-related sequence in GCD10 matchs the consensus sequence at 12 of these 14 positions (Fig. 2). Additional evidence that GCD10 contains a functional RRM is provided by the finding that GCD10 binds RNA in vitro (see below).

\section{GCD10 is an essential gene}

As shown in Figure 3, gcd10 mutations lead to temperature-sensitive growth under nonstarvation conditions, suggesting that GCD10 has an essential function beyond its role in GCN4 translational control. To test this pos- sibility directly, we constructed the deletion-insertion allele gcd10D::URA3 (see Fig. 1; pMG108) and used it to replace one copy of GCD10 in the diploid strains MGY1 and MGY2 (see Materials and methods). Tetrad analysis of each $\mathrm{Ura}^{+}$diploid transformant revealed that only

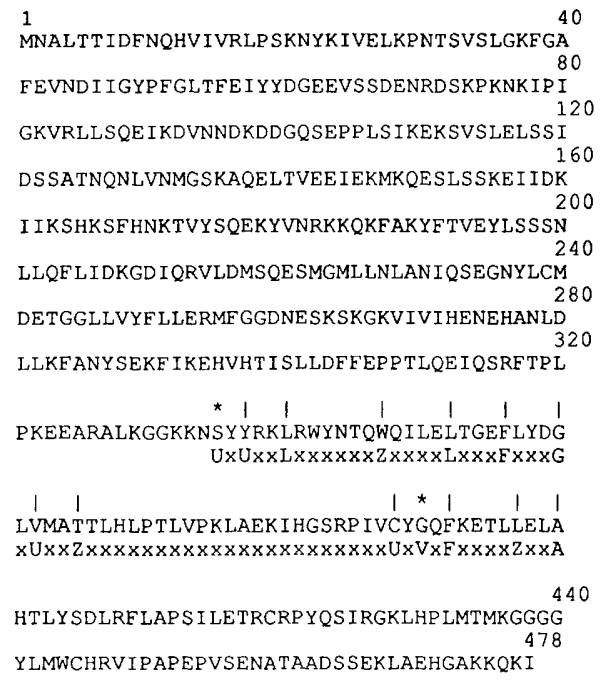

Figure 2. Deduced amino acid sequence of GCD10 and location of a presumptive RRM. The deduced amino acid sequence is given in single-letter code. The RRM sequence motif defined by Birney et al. (1993) is shown below the sequence at the location of the presumptive RRM in GCD10. (x) Any residue; (U) uncharged residues $L, I, V, A, G, F, W, Y, C, M ;(Z) U+S, T$. Conserved positions in the RRM that occur in GCDI0 are denoted by vertical lines above the sequence. The two conserved residues of the RRM motif lacking in GCD10 are denoted by the asterisks, $\left({ }^{*}\right)$ above the sequence, the position corresponding to Gly-390 in GCD10 is occupied by valine in most, although not all, RRM-containing proteins. 

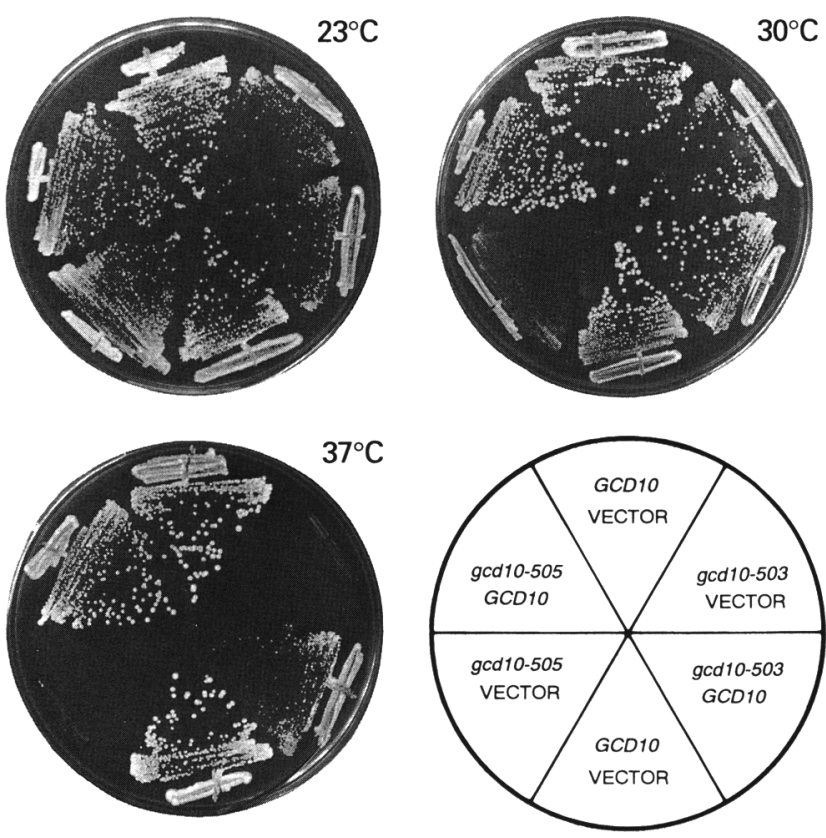

Figure 3. Temperature-sensitive growth phenotypes of gcd10 mutations. Strains carrying different alleles of $g c d 10$ were transformed with pMG107 bearing GCD10 or with the vector pRS316. Ura ${ }^{+}$transformants were streaked for single colonies on minimally supplemented synthetic-dextrose (SD) plates and incubated at $23^{\circ} \mathrm{C}, 30^{\circ} \mathrm{C}$, or $37^{\circ} \mathrm{C}$ for 4,3 , and 2 days, respectively. The $\operatorname{gcd} 10$ strains were $\mathrm{Hm} 298(\operatorname{gcd} 10-505)$ and $\mathrm{H} 62$ (gcd10-503). The wild-type strains were $\mathrm{H} 96$ (top sector), which is isogenic to $\mathrm{H} 62$, and $\mathrm{H} 117$ (bottom sector), that is congenic to Hm298. The gcd10-503 mutation appears to be semidominant.

two of the four spores in each of 20 asci could form colonies on rich medium after 7 days at $30^{\circ} \mathrm{C}$. All viable spores were $\mathrm{Ura}^{-}$and DNA blot-hybridization analysis of four such spore clones indicated the presence of wildtype GCD10 (data not shown). Microscopic examination of the dissection plates showed that the inviable gcd10D::URA3 spores germinated and divided several times before growth ceased. To confirm that GCD10 was the only essential gene whose function had been disrupted, we demonstrated that construct pMG120 containing the GCD10 ORF under the control of the GAL1 promoter could restore wild-type growth to haploid spores bearing the $g c d 10 \Delta:: U R A 3$ mutation (see Materials and methods).

\section{gcd 10 mutants are defective in translation initiation}

The finding that GCD10 is essential, plus the fact that all GCD genes characterized thus far encode essential components of the yeast translational machinery (Hannig et al. 1992, Lanker et al. 1992; Cigan et al. 1993), suggested to us that GCD10 is required for general translation initiation. To test this idea, we analyzed total polysome profiles in temperature-sensitive gcd10 mutants after incubating at the nonpermissive temperature. Despite an obvious reduction in the rate of colony for- mation on solid medium at $37^{\circ} \mathrm{C}$ (Fig. 3), none of our gcd10 mutants exhibit a marked growth defect in liquid medium after several hours of incubation at this temperature. However, we found that gcd10-504 strains are temperature sensitive for growth in liquid medium at $39^{\circ} \mathrm{C}$. Three hours after a temperature shift from $23^{\circ} \mathrm{C}$ to $39^{\circ} \mathrm{C}$, the gcd10-504 mutant $\mathrm{H} 255$ doubled every $2.5 \mathrm{hr}$, whereas the isogenic wild-type strain $\mathrm{Hl} 17$ had a doubling time of $1.5 \mathrm{hr}$, indicating a 1.7 -fold decrease in the growth rate of the mutant. Therefore, we analyzed polysome profiles in $\mathrm{H} 255$ and $\mathrm{H} 117$ after shifting from $23^{\circ} \mathrm{C}$ to $39^{\circ} \mathrm{C}$.

The polysome profiles of the mutant and wild-type strains grown at $23^{\circ} \mathrm{C}$ were similar; however, quantitation of the profiles shown in Figure 4 (panels labeled $23^{\circ} \mathrm{C}$ ) and others obtained at intermediate points on the growth curve, revealed a modest reduction in the polysome/monosome ratio in the mutant versus the wild type (Table 1). The wild-type strain showed very little difference in polysome content whether incubated at $23^{\circ} \mathrm{C}$ or $39^{\circ} \mathrm{C}$. In contrast, the mutant strain showed a progressive and marked reduction in the polysome to monosome ratio with increasing incubation at $39^{\circ} \mathrm{C}$ (Fig. 4; Table 1). Moreover, the average size of the polysomes decreased when the mutant was grown at $39^{\circ} \mathrm{C}$. The 2 -mers and 3 -mers represented $\sim 24 \%$ of the polysome mass in the mutant at the permissive temperature but comprised $\sim 40 \%$ of the polysomes after $4.5 \mathrm{hr}$ at $39^{\circ} \mathrm{C}$. In contrast, in the wild-type strain, 2-mers and 3-mers represented $23 \%$ and $27 \%$ of the polysome mass at $23^{\circ} \mathrm{C}$ and $39^{\circ} \mathrm{C}$, respectively (Fig. 4). When cycloheximide was added to block translation elongation before the temperature shift, no decrease in polysome size or content occurred in the mutant or wild-type strains (Fig. 4; Table 1). These last results imply that polysome runoff occurred at the nonpermissive temperature in the gcd10 mutant attributable to a specific decrease in the rate of translation initiation relative to elongation.

\section{Localization of GCD10 with the translational apparatus}

Having obtained evidence that GCD10 is required for general translation initiation in vivo, we wished to determine whether the protein is physically associated with the translational machinery. Toward this end, we raised antibodies against a $\operatorname{tr} E-G C D 10$ fusion protein containing the carboxy-terminal half of GCD10, and affinity-purified the serum using the TrpE-GCD10 fusion protein immobilized on filters (see Materials and methods). The purified antibodies detected a single protein on immunoblots of yeast cell extracts with an apparent molecular mass of $62 \mathrm{kD}$, somewhat greater than the predicted value for GCD10. This immunoreactive protein was much more abundant in a transformant containing $G C D 10$ on a high copy-number plasmid versus one containing vector alone (see below in Fig. 6D), confirming its identity as GCD10.

We investigated whether GCD10 is associated with ribosomes by fractionating cell extracts by velocity sed- 


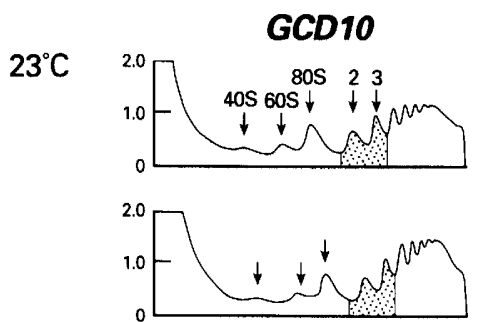

$39^{\circ} \mathrm{C}$
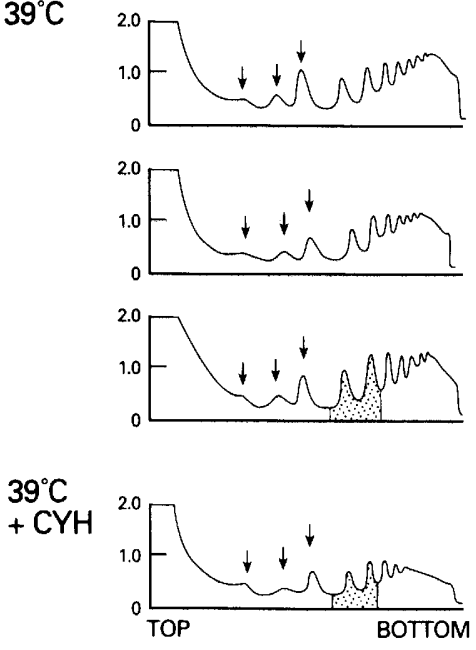
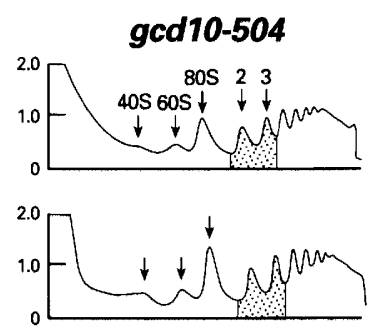

$4.5 \mathrm{~h}$
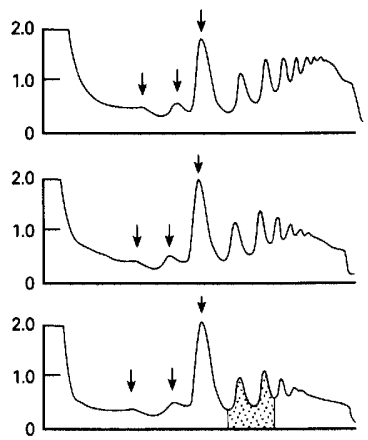

$3 \mathrm{~h}$

$4.5 \mathrm{~h}$

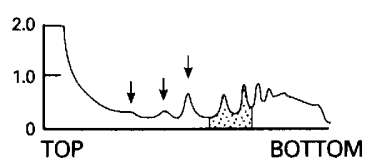

$\mathrm{t}=0$
Figure 4. Analysis of polysome profiles in isogenic GCD10 and gcd10-504 strains. The gcd10504 strain $\mathrm{H} 255$ and its isogenic wild-type parent $\mathrm{H} 117$ were grown at $23^{\circ} \mathrm{C}$. Half the culture was shifted to $39^{\circ} \mathrm{C}$, and samples were collected at the indicated times and processed for polysome analysis by velocity-sedimentation of whole cell extracts on sucrose gradients. Gradients were fractionated while scanning at $254 \mathrm{~nm}$, and the resulting absorbance profiles are shown, with the top of the gradients at left. The positions of $40 \mathrm{~S}, 60 \mathrm{~S}$, and $80 \mathrm{~S}$ ribosomal species, and the locations of 2 -mer (2) and 3-mer (3) polysomes are indicated by arrows. For each strain, the top two gradients correspond to the initial $(t=0)$ and the final $(t=4.5 \mathrm{hr})$ time points at the permissive temperature $\left(23^{\circ} \mathrm{C}\right)$. The middle three gradients correspond to the indicated times after the shift to the nonpermissive temperature $\left(39^{\circ} \mathrm{C}\right)$. For the bottom gradients, cycloheximide $(\mathrm{CYH})$ was added to the culture at the time of the temperature shift to $39^{\circ} \mathrm{C}$. The stippled 4.5 $\mathrm{h}$ areas under the profiles correspond to the fractions of the total absorbance profiles represented by 2-mer and 3-mer polysomes (see text). imentation on sucrose gradients to separate soluble proteins, ribosomal subunits, and polysomes, followed by immunoblot analysis of the gradient fractions using antiGCD10 antibodies. Extracts were prepared from exponentially growing wild-type cells with or without the addition of cycloheximide immediately before harvesting. Addition of cycloheximide inhibits translation initiation and elongation and thus stabilizes the polysomes throughout the experiment. Omission of the drug leads to polysome runoff in vitro and accumulation of $80 \mathrm{~S}$ particles lacking mRNA (80S couples) (Ramirez et al. 1991), presumably because elongation of nascent chains is com-

Table 1. Polysome to monosome ratios in isogenic GCD10 and gcd10-504 mutants

\begin{tabular}{|c|c|c|c|c|}
\hline \multirow{3}{*}{$\begin{array}{l}\text { Time }(\mathrm{hr}) \text { after } \\
\text { temperature shift }\end{array}$} & \multicolumn{4}{|c|}{ Polysome/monosome ratio in strain } \\
\hline & \multicolumn{2}{|c|}{ H117(GCD10) } & \multicolumn{2}{|c|}{$\mathrm{H} 255 \mid$ gcd10-504) } \\
\hline & $23^{\circ} \mathrm{C}$ & $39^{\circ} \mathrm{C}$ & $23^{\circ} \mathrm{C}$ & $39^{\circ} \mathrm{C}$ \\
\hline 0 & 7.1 & N.D. & 6.7 & N.D. \\
\hline 1.5 & 8.3 & 7.7 & 6.3 & 4.2 \\
\hline 3 & 9.1 & 9.1 & 4.5 & 2.3 \\
\hline 4.5 & 7.7 & 11.1 & 5.3 & 1.4 \\
\hline $4.5\left(+\mathrm{CYH}^{\mathrm{b}}\right)$ & 5.9 & 6.7 & 5.3 & 7.1 \\
\hline
\end{tabular}

${ }^{\text {a Ratios were calculated by summing the areas under the total }}$ polysomal and monosome peaks and dividing the first sum by the second sum.

${ }^{\text {b}}$ Cycloheximide was added to $50 \mu \mathrm{g} / \mathrm{ml}$ at the time of the temperature shift., pleted, whereas new initiation events occur infrequently in the cell extracts. Analysis of extracts prepared in the presence of cycloheximide (Fig. $5 \mathrm{~B}, \mathrm{C}$ ) showed that a small amount of GCD10 was found in the fractions containing polysomes and $\sim 35 \%$ of the total amount was present in fractions 5-11, containing the 40S-80S ribosomal species. Densitometric scanning of the data indicated reproducibly a small peak in fractions 6 and 7 that is expected to contain $43 \mathrm{~S}-48 \mathrm{~S}$ preinitiation complexes (Fig. $5 \mathrm{C}$ ). The majority of the GCD10 protein was present in fractions 2 and 3 . When cycloheximide was omitted, leading to dissociation of most of the polysomes (see legend to Fig. 5), we detected no GCD10 protein in the polysomal fractions and only $\sim 8 \%$ of the total amount in fractions 5-11 containing the 40S-80S species. The remainder of the GCD10 protein was present in fractions 2 and 3 . These results suggest that GCD10 is functionally associated with polysomes, $80 \mathrm{~S}$ ribosomes, and preinitiation complexes.

We also examined the sedimentation profile of GCD10 in extracts from a mutant strain containing a temperature-sensitive mutation in the $P R T 1$ gene, recently shown to encode a subunit of eIF-3 (Naranda et al. 1994; Danaie et al. 1995). In this strain, polysome runoff occurs after only a short incubation of cells at the nonpermissive temperature (Foiani et al. 1991) (see legend to Fig. 5). When we compared extracts obtained from a prt1-1 strain grown at the permissive $\left(23^{\circ} \mathrm{C}\right)$ and nonpermissive $\left(37^{\circ} \mathrm{C}\right)$ temperatures (Fig. 5A), we obtained results similar to those just described in Figure 5B for polysome runoff in wild-type extracts. At $23^{\circ} \mathrm{C}$, a small amount of 
Figure 5. Cosedimentation of a fraction of GCD10 with ribosomal subunits. (A) Total cell extracts were prepared from prt1-1 strain F294 grown at the permissive temperature $\left(23^{\circ} \mathrm{C}\right)$ to an $\mathrm{OD}_{600}$ of $\sim 0.2$ after which half of the culture was shifted to the nonpermissive temperature $\left(37^{\circ} \mathrm{C}\right)$ for $15 \mathrm{~min}$. Extracts were subjected to sucrose gradient fractionation as described in Materials and methods. Total proteins in each fraction were precipitated with TCA and analyzed by immunoblotting using affinity-purified antibodies against GCD10 (1:100 dilution). Immune complexes were detected using the enhanced chemiluminescence technique. The numbers across the top indicate the gradient fractions numbered from top to bottom. The lane preceding the gradient fractions contains $50 \mu \mathrm{g}$ of the corresponding yeast extracts before fractionation on the gradients. Arrows indicate the positions of $40 \mathrm{~S}$ and $60 \mathrm{~S}$ subunits, $80 \mathrm{~S}$ ribosomes, and polysomes as determined from the UV-absorbance profiles of the gradients in parallel (data not shown). The polysome/ monosome ratios at $23^{\circ} \mathrm{C}$ and $37^{\circ} \mathrm{C}$ calculated from these profiles were 3.8 and 1.0, respectively. $(B)$ Total cell extracts were prepared from wild-type strain $\mathrm{H} 1642$ in the presence $(+)$ or absence $(-)$ of cycloheximide $(\mathrm{CYH})$ and subjected to sucrose gradient fractionation and immunoblot analysis as in $A$. The polysome/monosome ratio in the presence of cycloheximide was 4.5 and decreased to 0.7 when the drug was omitted (data not shown). (C) Quantitation of the distribution of GCD10 protein in the gradient fractions. Densitometric scanning of lightly exposed autoradiograms from the experiment in $B$ was carried out for fractions $1-11$, and the percentage of the total absorbance present in each fraction was plotted against fraction number. The locations of various ribosomal species are indicated as determined by the UV-absorbance profiles of the gradients; the location of a $15 \mathrm{~S}$ species is indicated based on previous determinations of the position of the eIF-2-eIF-2B complex in these gradients (Cigan et al. 1991; Foiani et al. 1991).

GCD10 was found in the polysomal fractions and $80 \mathrm{~S}$ fractions and a substantial proportion was present in the 40S-60S fractions. At the nonpermissive temperature, we detected no GCD10 in the polysomal or $80 \mathrm{~S}$ fractions and a reduced proportion of the total protein in fractions 6 and 7 containing $43 \mathrm{~S}-48 \mathrm{~S}$ species (Fig. 5A). The finding that a significant fraction of GCD10 was present in polysomal and 40S-80S fractions under conditions where polysomes were intact, but not when polysomes were disrupted by impairing translation initiation in two different ways, strongly suggests that GCD10 interacts physically with translation initiation complexes.

\section{GCD10 copurifies with eIF-3}

In size-exclusion chromatography of a ribosomal salt wash on a Superose- 6 column, the majority of GCD10 eluted with an apparent molecular mass of $\sim 550,000$ (data not shown). This observation, combined with the involvement of GCD10 in general translation, led us to consider the possibility that GCD10 is the subunit of yeast eIF- 3 that was assigned an $M_{r}$ of 62,000 by Naranda et al. (1994). These workers purified eIF-3 by its ability to stimulate synthesis of methionyl-puromycin (Met-PM), a reaction that mimics formation of the first peptide bond, in assays containing all of the required initiation
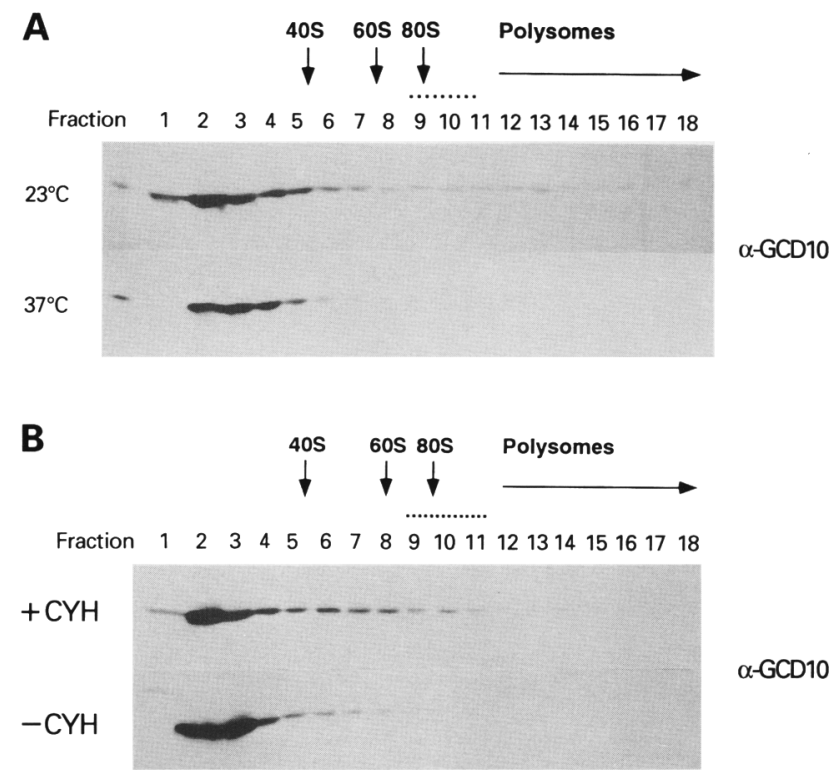

$\alpha-G C D 10$

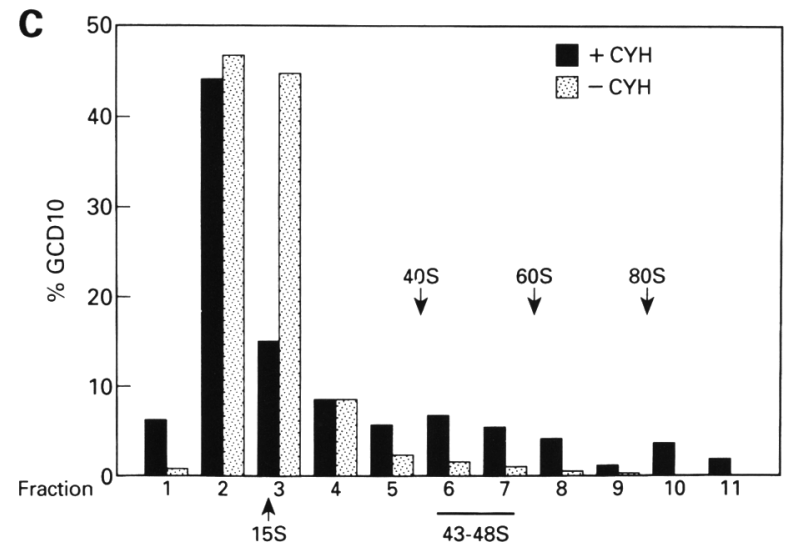

factors purified from HeLa cells except eIF-3. Yeast eIF-3 could substitute functionally for the corresponding HeLa factor in stimulating Met-PM synthesis in these assays. Analysis of the purified factor indicated that the eIF-3 of $S$. cerevisiae is a complex of eight subunits with an apparent molecular mass of $\sim 550 \mathrm{kD}$ (Naranda et al. 1994).

To determine whether GCD10 is a subunit of eIF-3, we asked first whether GCD10 coelutes with eIF-3 from a Mono-S column in the final step of purifying yeast eIF-3 according to the protocol of Naranda et al. (1994). As shown in Figure 6A, a peak of eIF-3 activity corresponding to approximately fivefold stimulation in the Met-PM assay eluted in fractions 10 to 12 . Immunoblot analysis of these fractions with crude polyclonal antiserum against the entire eIF- 3 complex showed that only fractions 10 to 11 contained all eight major polypeptides that were identified previously as subunits of yeast eIF-3 (Naranda et al. 1994). Each of the immunoreactive bands assigned to eIF-3 is visible in Figure 6B lexcept for the smallest subunit p16 that ran off the gel); the additional bands are thought to be degradation products of the 
A

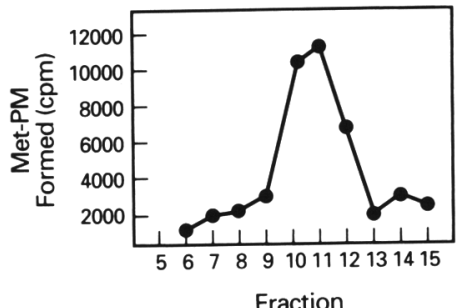

B

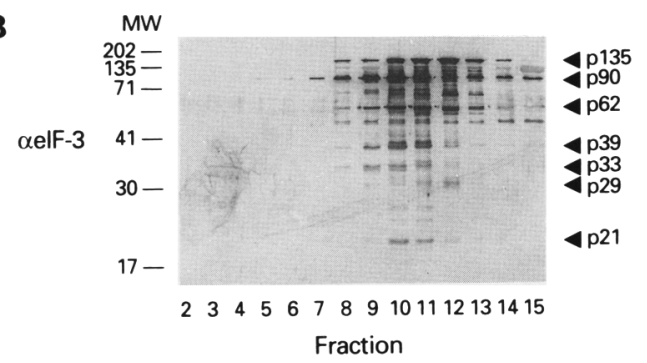

C

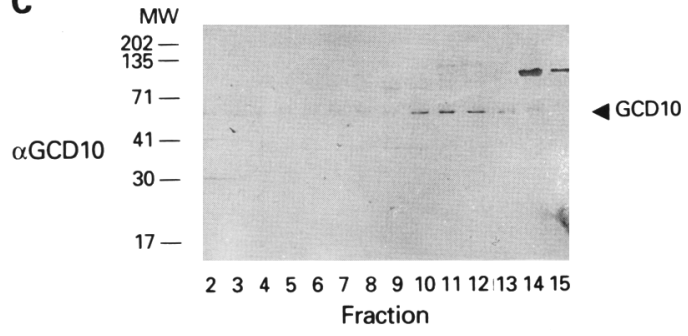

D

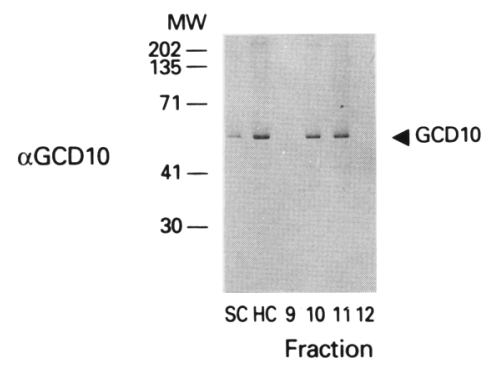

Figure 6. Coelution of GCDI0 with the yeast eIF-3 complex in ion-exchange chromatography. Fractions from Mono-S $5 / 5$ column chromatography carried out in the final step in purifying the yeast elF-3 complex were assayed in parallel for eIF- 3 activity, eIF-3 subunits, and for GCD10 protein. $(A)$ Assay of eIF-3 biochemical activity. Ten microliters of each fraction was tested for stimulation of Met-PM/synthesis in reactions containing mammalian washed ribosomes and initiation factors (see Materials and methods). The activity is reported as counts per minute of $\left[{ }^{3} \mathrm{H}\right]$ Met-PM formed in the reaction. In control experiments, no stimulation was obtained when eIF-3 was omitted, whereas approximately fivefold stimulation of Met-PM synthesis was seen when $3.1 \mu \mathrm{g}$ of purified HeLa eIF-3 was added. The background value (1123 $\mathrm{cpm}$ ) obtained with the charged tRNA alone was subtracted. $(B)$ Immunoblot analysis of total eIF-3 subunits. Fifteen-microliter aliquots of fractions 2-15 were analyzed by $10 \%$ SDS-PAGE and immunoblotting using rabbit polyclonal antiserum against eIF-3, and immune complexes were visualized using alkaline phosphatase-conjugated antibodies against rabbit IgG (see Materials and methods). The column fraction numbers are indicated at the bottom, the migration of molecular mass markers is indicated at left, and the migration of the seven largest subunits of elF-3 and their masses in $\mathrm{kD}$ are shown at right (Naranda et al. 1994). (C) Immunoblot analysis of GCD10. The analysis was performed as in $B$, except that the affinity-purified anti-GCDI0 antiserum was used as the source of primary antibodies. The arrowhead at right indicates the migration of $G C D 10$ as deduced from the experiment shown in $D$. (D) Immunoblot analysis of GCD10 in the peak fractions containing eIF-3 in parallel with whole cell extracts prepared from strains overexpressing GCD10. Twenty-microliter aliquots of Mono-S fractions 9-12, containing the peak of elF-3 activity, and $20 \mu \mathrm{g}$ aliquots of whole cell extracts from strain $\mathrm{H} 1642$ transformed with vector alone (SC) or high copy-number plasmid pE107 bearing GCD10 plasmid $(\mathrm{HC})$, were analyzed in parallel by $8 \%$ SDS-PAGE and immunoblotting using affinity-purified antibodies against GCD10, as described for the experiment in $C$. The migration of molecular mass markers and their mass in $\mathrm{kD}$ is shown at left; the arrowhead at right indicates the position of GCD10. larger subunits. Consistent with previous findings (Naranda et al. 1994), the fractions immediately flanking 10 and 11 , which lack some of the smaller eIF-3 subunits, show reduced (fraction 12) or no activity (fractions 9 and 13) in the Met-PM assay compared to fractions 10 and 11 .

Immunoblot analysis of these column fractions, using affinity-purified anti-GCD10 antibodies, revealed an immunoreactive polypeptide with an apparent molecular mass of $\sim 62 \mathrm{kD}$ that peaks in fractions 10 to 12 . The polypeptide detected with anti-GCD10 antibodies and the $\sim 62-\mathrm{kD}$ subunit of eIF-3 detected with anti-eIF- 3 antibodies by Naranda et al. (1994) showed similar mass distributions across the column fractions (Fig. 6B,C). To demonstrate that the $62-\mathrm{kD}$ polypeptide detected with anti-GCD10 antibodies in column fractions $10-12$ has the same molecular mass as GCD10, we analyzed the Mono-S column fractions containing eIF-3 activity in parallel with whole cell extracts containing overexpressed GCD10 protein. As shown in Figure 6D, the
GCD10 protein detected in cell extracts and the immunoreactive species in purified eIF-3 have identical mobilities in SDS-PAGE. Taken together, the results in Figure 6 indicate that GCD10 coelutes from the Mono-S column with eIF-3 activity and is identical in mass to the 62-kD subunit of yeast eIF-3 identified by Naranda et al. (1994). GCD10 was found at much lower levels in fraction 12 in Figure 6D than in Figure 6C. We attribute this difference to degradation of the protein during storage before conducting the analysis shown in Figure 6D. We presume that GCD10 is less stable in eIF-3 complexes lacking the smaller subunits, the latter being underrepresented in fraction 12 versus fractions 10 and 11 .

\section{GCD10 coimmunoprecipitates with PRT1, a known subunit of eIF-3}

To provide additional evidence that GCD10 is a subunit of yeast eIF-3, we asked whether it could be coimmunoprecipitated with the PRT1 protein, a known subunit of 
eIF-3 (Naranda et al. 1994; Danaie et al. 1995). The ribosomal high-salt wash fraction (HSW) or purified eIF-3 from the Mono-S fractions described above (Fig. 6) was immunoprecipitated with antibodies against PRT1, GCD10, or eIF-3, and the resulting immune complexes were probed by immunoblot analysis for PRT1, GCD10, and the other subunits of eIF-3 using the same antisera. Each of the three antisera immunoprecipitated similar quantities of PRT1 and GCD10 from the HSW and from the Mono-S peak fractions (Fig. 7). We estimated that $50 \%-70 \%$ of the GCD10 and PRT1 in the starting material was recovered in the immunoprecipitates. Control immunoprecipitations carried out with preimmune sera or with antibodies against initiation factor eIF-1A /ChiaLin et al. 1995/ did not precipitate detectable amounts of GCD10 or PRT1 (Fig. 7), whereas the eIF-1A antibodies immunoprecipitated eIF-1 A from the HSW fraction (data not shown). These results provide strong evidence that GCD10 and PRT1 are components of the same protein complex. Probing the immune complexes with antibodies against eIF-3 showed that the p135 subunit of eIF-3 (Naranda et al. 1994) was also coimmunoprecipitated with GCD10 and PRT1 whether using the antibodies against PRT1, GCD10, or eIF-3 to immunopurify the complex (data not shown). The results in Figure 7 provide strong evidence that GCDI0 is an integral component of yeast eIF-3.

\section{GCD10 is the RNA-binding subunit of eIF-3}

The yeast eIF-3 complex has RNA-binding activity, and this activity has been used to affinity-purify all eight subunits of the complex (Naranda et al. 1994). Because the $62-\mathrm{kD}$ subunit was the only one found to bind RNA as an isolated polypeptide, it was believed to be responsible for the RNA-binding activity of the entire eIF-3 complex. To provide additional proof that GCD10 is identical to the $62-\mathrm{kD}$ subunit of eIF-3 identified by Naranda et al. (1994), we asked whether GCD10 has RNA-binding activity. We began by conducting Northwestern analysis of whole cell extracts from strains containing high-copy versus single-copy GCD10 using an RNA transcript corresponding to the $5^{\prime}$-untranslated region of Xenopus $\beta$-globin mRNA as the probe. As shown in Figure 8A (lanes $\mathrm{HC}$ and $\mathrm{SC}$ ), an RNA-binding protein with the same apparent molecular mass of GCD10 was present at much higher levels in the cell extracts derived from the strain containing high copy-number versus low copy-number GCD10. In contrast, the RNA-binding proteins of lower molecular mass (possibly ribosomal proteins) were present at roughly the same levels in the two extracts. These results indicate that GCD10 has RNA-binding activity. In parallel, we carried out Northwestern analysis on the same Mono-S column fractions containing eIF-3 activity described above. As shown previously (Naranda et al. 1994), fractions 10 and 11 containing the peak of eIF-3 activity (see Fig. 6A) also contained peak amounts of the RNA-binding subunit of eIF-3. This RNA-binding protein coeluted

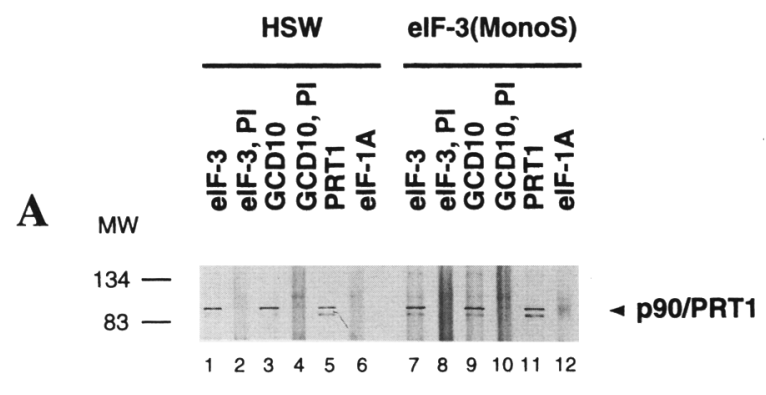

B

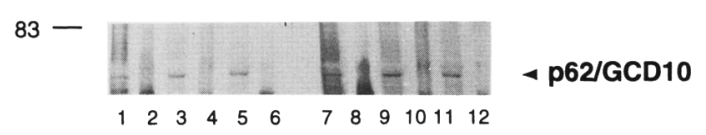

Figure 7. Coimmunoprecipitation of GCD10 with the $90-\mathrm{kD}$ subunit of eIF-3. Approximately $50 \mu \mathrm{g}$ of total proteins from the ribosomal high salt wash (HSW) and $4 \mu \mathrm{g}$ of purified eIF-3 complex [eIF-3 (MonoS)] were immunoprecipitated with polyclonal antibodies against eIF-3 (lanes 1,7), GCDI0 (lanes 3,9), PRT1 (lanes 5,11), elF-1A (lanes 6,12), or the preimmune (PI) sera corresponding to the eIF-3 (lanes 2,8) and GCD10 (lanes 4,10) antibodies. The immune complexes were separated by $10 \%$ SDSPAGE, transferred to nitrocellulose, and probed with polyclonal antibodies against PRT1 $(A)$ and GCD10 $(B)$.

and comigrated with GCD10 (Fig. 8A). When the same filter probed with labeled RNA shown in Figure 8A (right) was subsequently probed with antibodies against GCD10 (Fig. 8A, left), we found that the mobilities of the RNA-binding polypeptide and the immunoreactive protein in the fractions containing the peak of eIF-3 activity coincided exactly. These results provide strong evidence that GCD10 is the RNA-binding subunit of eIF-3.

The mammalian eIF- 3 is similar to the yeast factor in both size and number of subunits. In addition, the $66-\mathrm{kD}$ subunit of HeLa eIF-3, like GCD10, has RNA-binding activity (Westermann and Nygard 1984; B.J. Fabbri and J.W.B. Hershey, unpubl.). These considerations, combined with the functional interchangeability of yeast and HeLa eIF- 3 in the Met-PM synthesis assay (Naranda et al. 1994), led us to investigate whether the GCD10 subunit of yeast eIF-3 and the p66 subunit of mammalian eIF-3 have structural similarities. To examine this possibility, we carried out immunoblot analysis of purified HeLa and rabbit eIF-3 using our anti-GCD10 antibodies. As shown in Figure 8B, the GCD10 antibodies reacted specifically with the p66 subunit of human eIF-3, but not with the corresponding subunit of rabbit eIF-3. Northwestern analysis of the same samples confirmed that nearly equivalent amounts of the GCD10 subunit of yeast eIF-3 and the p66 subunits of the two mammalian factors had been loaded on the gel (Fig. $8 \mathrm{~B}$ ). These results suggest that yeast GCD10 and HeLa p66 share one or more epitopes that are recognized by our GCD10 antibodies, and they provide additional evidence that GCD10 is the RNA-binding subunit of yeast eIF-3. 



Figure 8. GCD10 has RNA-binding activity and is related immunologically to the RNA-binding subunit of human eIF-3. (A, right) ${ }^{32}$ P-labeled mRNA. Northwestern analysis was carried out on fractions 8-13 from the Mono-S column containing the peak of eIF-3 activity and several flanking fractions in parallel with the whole cell extracts containing wild-type levels (SC) or overexpressed levels $(\mathrm{HC})$ of GCD10 protein. Aliquots of the Mono-S fractions containing $\sim 150 \mathrm{ng}$ of protein and $15-\mu \mathrm{g}$ aliquots of the whole cell extracts were resolved by $9 \%$ SDS-PAGE, transferred to nitrocellulose, hybridized with a ${ }^{32} \mathrm{P}$-labeled $\beta$-globin transcript and subjected to autoradiography, all as described in Materials and methods. $(A$, left $) \alpha$-GCDl0. The same membrane filter subjected to Northwestern analysis on the right was blocked with blotto for $\mathrm{l} \mathrm{hr}$ and incubated with anti-GCD10 antibodies (1:100 dilution). The immune complexes were visualized exactly as in Fig. 6 . The presumptive GCD10 bands labeled by ${ }^{32} \mathrm{P}$-labeled mRNA in the Northwestern blot at right were superimposed precisely on the immunoreactive GCD10 bands in the immunoblot at left. (B) Approximately 500 ng of purified yeast $(\mathrm{Y}), \mathrm{HeLa}(\mathrm{H})$, and rabbit reticulocyte (R) eIF-3 complexes were separated by $8 \%$ SDS-PAGE and subjected to immunoblot and Northwestern analysis as described in $A$. The arrowheads indicate the migration of yeast GCD10.

\section{Discussion}

Evidence that GCD10 is an essential subunit of eIF-3

Mutations in GCD10 were identified originally by their ability to restore efficient GCN4 expression in mutants lacking the protein kinase GCN2 (Harashima and Hinnebusch 1986). It was established that gcd10 mutations increase GCN4 expression at the translational level by overcoming the inhibitory effects of the uORFs on ribosomal reinitiation at the GCN4 start site (Mueller et al. 1987). We showed here that the GCD10 product has an essential function in general translation initiation (Fig. 4) in addition to its gene-specific role in regulating GCN4 expression. Most of the GCD10 protein in cell extracts was found in a high molecular mass complex of $\sim 550 \mathrm{kD}$, and a fraction appears to be associated with translating ribosomes or $43 \mathrm{~S}$ to $48 \mathrm{~S}$ preinitiation complexes (Fig. 5). Our affinity-purified antibodies against GCD10 cross-reacted with a polypeptide with an apparent molecular mass of 62,000 that coeluted from a Mono-S column in the same fractions that contain the major eight subunits of yeast eIF-3 and the biochemical activity ascribed to this factor in stimulating Met-PM synthesis (Fig. 6) (Naranda et al. 1994). Similar results were obtained by assaying column fractions from Superose-6 gel filtration chromatography (data not shown), the step preceding Mono-S chromatography in the purification of yeast eIF-3 (Naranda et al. 1994). In addition to observing copurification of GCD10 with the biochemical activity and protein subunits of eIF-3, we found that GCD10 could be specifically coimmunoprecipitated with the PRT1-encoded and $135-\mathrm{kD}$ subunits of eIF-3 using antibodies against GCD10, PRT1, or eIF-3 (Fig. 7).
On the basis its molecular mass, GCD10 should correspond to the $62-\mathrm{kD}$ subunit of eIF-3 that was shown previously to have RNA-binding activity (Naranda et al. 1994). We confirmed this prediction by showing that GCD10 binds RNA in a Northwestern assay and that the RNA-binding subunit of eIF-3 and the polypeptide recognized by anti-GCD10 antibodies coelute from Mono-S and comigrate precisely in SDS-PAGE (Fig. 8). Finally, we showed that the anti-GCD10 antibodies specifically recognized the 66-kD RNA-binding subunit of human eIF-3 (Fig. 8). The fact that the RNA-binding activity of eIF-3 can be used to affinity-purify all eight subunits of the complex provides additional evidence that GCD10, the only subunit known to bind RNA (Naranda et al. 1994), is an integral component of the eIF-3 complex. On the basis of all these results, we conclude that GCD10 encodes the RNA-binding subunit of yeast eIF-3.

\section{The role of GCD10 and eIF-3 in GCN4 translational control}

According to our model for GCN4 translational control, ribosomes translate $\mathrm{UORF} 1$ and reinitiate very efficiently at uORFs 2,3 , or 4 when amino acids are abundant. These ribosomes cannot reinitiate again and translation of GCN4 is repressed. Under starvation conditions, reinitiation at uORFs $2-4$ is suppressed partially and many ribosomes are able to reinitiate at GCN4 instead (Abastado et al. 1991). The failure of ribosomes to reinitiate at uORFs 2-4 in amino acid-starved cells requires phosphorylation of eIF-2 by the protein kinase 
GCN2 (Dever et al. 1992). A large body of genetic and biochemical evidence indicates that phosphorylated eIF-2 down-regulates eIF-2B in yeast, decreasing the level of active eIF- 2 in the cell and the concentration of eIF2/GTP/Met-tRNA Met $_{i}$ ternary complexes (Hinnebusch 1992; Cigan et al. 1993; Vazquez de Aldana and Hinnebusch 1994). This is expected to reduce the rate at which ternary complexes rebind to ribosomes scanning downstream from uORFl. As a result, many ribosomes will reach the start sites of uORFs 2-4 lacking the ternary complex and continue scanning downstream. Essentially all of these ribosomes will rebind the ternary complex before reaching the GCN4 start site and reinitiate there instead (Dever et al. 1992).

Mutations in each of the genes encoding subunits of eIF- 2 or eIF-2B have been isolated that mimic eIF- $2 \alpha$ phosphorylation in causing a reduction in general translation initiation and constitutive derepression of GCN4 translation (Hinnebusch 1992). These mutations bypass the requirement for GCN2 for efficient translation of GCN4 mRNA. Because the mutations we isolated in GCD10 have the same characteristics as those affecting

Figure 9. Model for the effects of gcd10 mutations on GCN4 translational control. Translation of GCN4 mRNA under nonstarvation conditions is depicted in wild-type cells $(A)$, where $G C N 4$ translation is repressed, and in $\operatorname{gcd} 10$ mutants $(B)$, where GCN4 translation is derepressed. GCN4 mRNA is shown with uORFs 1 and 4 and the beginning of the GCN4-coding sequences indicated as boxes. The $40 \mathrm{~S}$ ribosomal subunits are shown lightly shaded when associated with eIF-3 and densely shaded when associated with both eIF-3 and the eIF2.GTP.tRNA ${ }_{i}^{\text {Met }}$ ternary complex (TC) and, thus, fully competent to initiate translation. Unshaded 40S subunits lack the ternary complex and therefore cannot reinitiate. We assume that $40 \mathrm{~S}$ subunits contain both eIF- 3 and the ternary complex before they bind to the $5^{\prime}$ end of the mRNA and initiate the scanning process. The structural genes encoding the three subunits of eIF- 2 and five subunits of elF- $2 B$ are listed in boxes; genes encoding only two of the eight subunits of eIF- 3 have been identified thus far. After translation of uORFl, 40S subunits remain on the mRNA and continue scanning. Both eIF- 3 and the ternary complex must rebind to these ribosomes before they reach uORF4 to reinitiate at this site. After translation of uORF4, ribosomes dissociate from the mRNA and fail to reinitiate at GCN4. Under nonstarvation conditions, eIF-2.GDP is readily recycled to eIF-2.GTP by eIF-2B, leading to high levels of eIF-2-GTP and ternary complex formation. $(A)$ In wild-type cells, eIF- 3 binds rapidly to $40 \mathrm{~S}$ ribosomes after termination at uORF1, allowing ternary complex to rebind before the 435 complex reaches uORF4. Reinitiation occurs at uORF4, and GCN4 translation is repressed. $(B)$ In gcd10 mutants rebinding of ternary complex is delayed because of a defect in eIF-3, allowing many ribosomes to scan past uORF4 and reinitiate farther downstream at GCN4 instead. In the scenario depicted here, binding of eIF- 3 to the 40 S subunit is delayed until after many ribosomes have scanned past uORF4. Another possibility not depicted is that the mutant eIF- 3 binds to 40 S subunits but it is impaired in its ability to stimulate binding of the ternary complex. Consequently, many $40 S$ subunits do not rebind the ternary complex until after bypassing uORF4. subunits of eIF-2 or eIF-2B, we suspected that GCD10 might be involved in the formation of eIF-2/GTP/Met$\mathrm{tRNA}_{\mathrm{i}}^{\mathrm{Met}}$ ternary complexes or in stimulating the binding of these complexes to $46 \mathrm{~S}$ complexes consisting of eIF-3 and $40 S$ ribosomal subunits. Our identification of GCD10 as a subunit of yeast eIF-3 confirms this prediction because this multisubunit factor is a critical constituent of the $43 \mathrm{~S}$ preinitiation complex, and one of its functions identified by in vitro experiments is to stimulate binding of the ternary complex to small ribosomal subunits (Benne and Hershey 1978; Trachsel and Staehelin 1979; Feinberg et al. 1982).

Biochemical studies on mammalian eIF-3 have implicated this factor in several steps of the initiation process, including dissociation of $80 \mathrm{~S}$ ribosomes into free $60 \mathrm{~S}$ subunits and $46 \mathrm{~S}$ preinitiation complexes containing eIF-3 and $40 \mathrm{~S}$ subunits, binding of eIF-2/GTP/MettRNA $_{i}^{\text {Met }}$ ternary complexes to form $43 \mathrm{~S}$ complexes, and binding of mRNA to $43 \mathrm{~S}$ complexes containing both eIF-3 and the ternary complex (Benne and Hershey 1978; Trachsel and Staehelin 1979). Because ribosomes are already bound to GCN4 mRNA after translating uORF1, it

A
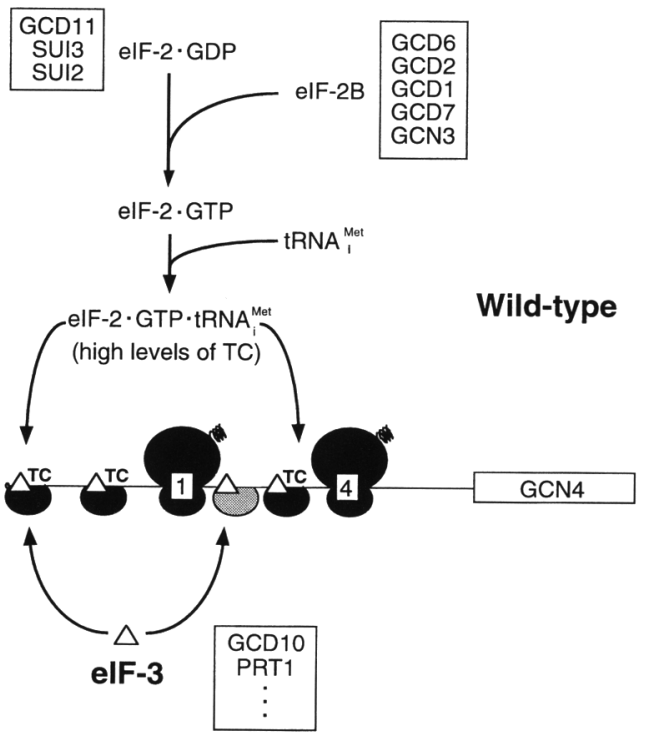

B

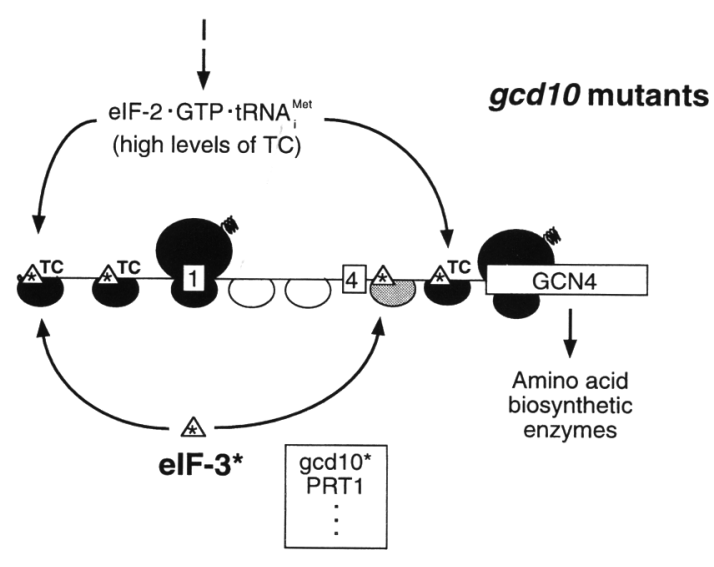


seems unlikely that gcd10 mutations derepress GCN4 expression by reducing the ability of eIF-3 to stimulate mRNA binding to $43 \mathrm{~S}$ complexes. Such a defect might be expected to reduce GCN4 mRNA translation $/ \mathrm{Gcn}^{-}$phenotypel by causing $43 S$ complexes to dissociate from the mRNA as they scan downstream from uORF1. A more likely possibility is that the $g c d 10$ mutations reduce the ability of eIF-3 to rebind to $40 \mathrm{~S}$ subunits and form $46 \mathrm{~S}$ complexes after translation termination at uORF1. This would result in "naked" 40 S subunits scanning downstream from uORF1 having a reduced ability to rebind ternary complexes (Fig. 9). Alternatively, it is possible that $\operatorname{gcd} 10$ mutations decrease the ability of eIF-3 to stimulate binding of eIF-2/GTP/Met-tRNA $A_{i}^{\text {Met }}$ ternary complexes to $46 \mathrm{~S}$ complexes rather than delaying the formation of these complexes after termination at uORF1. Either of these defects would decrease the rate at which ternary complexes rebind to $40 S$ subunits scanning downstream from uORF1, explaining why gcd10 mutations cause ribosomes to ignore uORFs $2-4$ and reinitiate at GCN4 in the absence of eIF-2 phosphorylation by GCN2 (Fig. 9).

GCD10 has RNA-binding activity (Naranda et al. 1994; Fig. 8) and the deduced amino acid sequence of the protein contains a relatively good match to the RRM consensus sequence (Fig. 2). It has been shown that the 66-kD subunit of mammalian eIF-3 can be cross-linked to $18 \mathrm{~S}$ rRNA in $46 \mathrm{~S}$ complexes (Nygard and Westermann 1982). If an interaction between yeast GCD10 and a site in 18S rRNA is important for binding of yeast eIF-3 to 40S subunits, then gcd10 mutations might disrupt this interaction and delay the rebinding of eIF-3 to $40 \mathrm{~S}$ subunits after termination at uORF1, as suggested above (Fig. 9). It has also been reported that mammalian p66 can be cross-linked to mRNA in $48 \mathrm{~S}$ preinitiation complexes (Westermann and Nygard 1984), leading to the notion that p66 could bridge an interaction between mRNA and $18 \mathrm{~S}$ in a manner reminiscent of the ShineDelgarno mRNA-16S rRNA base-pairing interaction in prokaryotes. It seems less likely that disrupting this interaction would derepress GCN4 translation efficiently because it should equally impair initiation events at uORFs $2-4$ and at GCN4.

After translating uORFl, ribosomes must rebind all of the factors required to reinitiate translation in the time it takes to scan the $\sim 200$ nucleotides separating uORF1 from uORF4; otherwise, they will bypass uORFs $2-4$ and reinitiate at GCN4 instead. This strict temporal requirement for reinitiation at the uORFs is thought to be one factor that makes GCN4 translation much more responsive to the levels of the eIF-2/GTP/Met-tRNA ${ }_{i}^{\text {Met }}$ ternary complex than are initiation events on conventional mRNAs lacking uORFs. As a result, GCN4 is a sensitive indicator of the in vivo functions of eIF-2, eIF-2B, and eIF-2 $\alpha$ kinases (Dever et al. 1993; Hinnebusch 1994; Romano et al. 1995). The fact that a subunit of eIF-3 has now been identified genetically by its effects on GCN4 translational control suggests that this regulatory mechanism can be used as an in vivo assay for this interesting and complex translation initiation factor.

\section{Materials and methods}

Strains, media, and genetic methods

The genotypes and origins of all yeast strains are summarized in Table 2 . Hm 47 and $\mathrm{Hm} 44$ were constructed by crossing $\mathrm{H} 1262$ to $\mathrm{H} 752$. $\mathrm{Hm} 203$ was selected as an $\mathrm{AT}^{\mathrm{R}}$ spore from a cross between $\mathrm{Hm} 19$ and H742. MGY3 was selected as a $\mathrm{Ura}^{+} \mathrm{Tsm}^{-}$ $\mathrm{His}^{-}$derivative from a cross between RS191 and Hm270. Transformation of yeast strains was carried out according to Ito et al. (1983). Standard genetic techniques and media were as described by Sherman et al. (1974). Amino acid analog sensitivity was tested as described before (Hinnebusch and Fink 1983b). Escherichia coli strain HB101 (BRL) was used for plasmid propagation and production of $\operatorname{trp} E$ fusion proteins. E. coli strain MV1 190 (BRL) was used for generating ssDNA from M13 derivatives used in sequencing experiments.

\section{Cloning of GCD10}

GCD10 was cloned by complementation of the 3-AT-resistant $\left(\mathrm{AT}^{\mathrm{R}}\right)$ and thermosensitive $\left(\mathrm{Tsm}^{-}\right)$phenotypes of $\mathrm{Hm} 47$ using a genomic library constructed in the low copy-number plasmid YCp50 (Rose et al. 1987). Plasmid DNA was recovered from yeast transformants as already described (Devenish and Newlon 1982) and used to transform E. coli HB101. Plasmid pMGl and its subclone pMG107 (Fig. 1) were shown to complement the $\mathrm{AT}^{\mathrm{R}}$ and $\mathrm{Tsm}^{-}$phenotypes in strains carrying gcd10-501, gcd10-502, gcd10-504, or gcd10-505. In contrast, the gcd10-503 allele in strain $\mathrm{H} 62$ was complemented only partially, suggesting that this allele is semidominant. To prove that pMG1 contains authentic GCD10 the $3.45-\mathrm{kb}$ HindIII fragment was inserted into YIp5 (Parent et al. 1985), and the resulting plasmid (pI 105) was digested at two closely spaced $\mathrm{HpaI}$ sites in the genomic sequences and used to transform $\mathrm{Hm} 47$ (MATagcn2::LEU2 gcd10-504 ura3-52) to $\mathrm{Ura}^{+} \mathrm{AT}^{\mathrm{S}} \mathrm{Tsm}^{+}$. DNA blot-hybridization analysis (Sambrook et al. 1989) revealed that pI105 had integrated at the presumptive GCD10 locus in the transformants we analyzed. One such transformant, Hm270 (Table 2), was crossed to Hm5l (MATa gcn2::LEU2 gcd10-504 ura3-52), which is $\mathrm{Ura}^{-} \mathrm{AT}^{\mathrm{R}} \mathrm{Tsm}^{-}$. The resulting diploids were sporulated and subjected to tetrad analysis. In all 21 tetrads analyzed, only parental ditypes were found for the Ura, AT, and Tsm phenotypes, indicating that the site of pI105 integration was linked to GCD10.

\section{Plasmid constructions}

The subclones constructed from pMG1 are summarized in Figure 1. Digestion of pMGl with ClaI yielded a 3.8-kb fragment beginning $\sim 340 \mathrm{bp}$ in the vector and ending at the unique ClaI site in the genomic insert that was inserted at the ClaI site of YCp50 to generate pMG101; pMG102 was constructed by religating the ClaI fragment containing the vector backbone derived from the same digestion. pMG103 was constructed by inserting the BamHI-SalI fragment from pMGl/the SalI site is present in the vector backbonel into the corresponding sites in YCp50. pMG104 was constructed from pMG1 by digestion with $X h o I$ and SalI, followed by religation. The 3.45-kb HindIII fragment from pMGl was inserted into the HindIII site of YCp50 to generate pMG105. pI105 contains the same 3.45-kb HindIII fragment as pMG105 inserted at the HindIII site of YIp5 (Struhl et al. 1979). pMG107 was constructed by inserting the XbaI-XhoI fragment containing the complete GCD10-coding sequence and $\sim 1 \mathrm{~kb}$ downstream of the gene at the $\mathrm{XbaI}$ and $\mathrm{XhoI}$ sites in the polylinker of pRS316 (Sikorski and Hieter 1989). pE107 was constructed by inserting the XbaI-XhoI fragment into pRS426 
Table 2. Yeast strains

\begin{tabular}{|c|c|c|}
\hline Strain & Genotype & Source \\
\hline H96 & a gcn2-101 gcn3-101 his1-29 ura3-52 [HIS4::1acZ, ura3-52] & Harashima and Hinnebusch (1986) \\
\hline $\mathrm{H} 54$ & a gcn2-101 gcn3-101 his1-29 gcd10-501 ura3-52 [HIS4::1acZ, ura3-52] & Harashima and Hinnebusch (1986) \\
\hline H55 & a gcn2-101 gcn3-101 his1-29 gcd10-502 ura3-52 [HIs4::1acZ, ura3-52] & Harashima and Hinnebusch (1986) \\
\hline $\mathrm{H} 62$ & a gcn2-101 gcn3-101 his1-29 gcd10-503 ura3-52 [HIS4::1acZ, ura3-52] & Harashima and Hinnebusch (1986) \\
\hline $\mathrm{H} 117$ & a gcn2-101 gcn3-101 his1-29 ura3-52 ino1 [HIS4::1acZ, URA3] & Harashima and Hinnebusch (1986) \\
\hline $\mathrm{H} 174$ & a gcn2-101 gcn3-101 his1-29 gcd10-505 ura3-52 ino1 [HIS4::lacZ, URA3] & Harashima and Hinnebusch (1986) \\
\hline $\mathrm{H} 255$ & a gcn2-101 gcn3-101 his1-29 gcd10-504 ura3-52 ino1 [HIS4::lacZ, URA3] & Harashima and Hinnebusch (1986) \\
\hline $\mathrm{H} 742$ & a gcn3::LEU2 lys2 leu2-3 leu2-112 & Harashima and Hinnebusch (1986) \\
\hline $\mathrm{H} 752$ & $\alpha$ gcn2::LEU2 ura3-52 leu2-3 leu2-112 & Harashima and Hinnebusch (1986) \\
\hline $\mathrm{H} 1262$ & 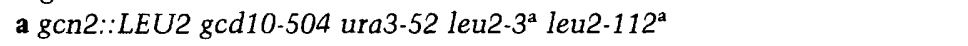 & this study \\
\hline $\mathrm{H} 1514$ & $\alpha$ ura3-52 trp1-63 leu2-3 leu2-112 & this study \\
\hline $\mathrm{H} 1515$ & a ura3-52 trp1-63 leu2-3 leu2-112 & Dever et al. (1992) \\
\hline $\mathrm{H} 1642$ & a ura3-52 leu2-3 leu2-112 trp1-63 [GCN4::lacZ, TRP1] & Dever et al. (1992) \\
\hline $\mathrm{Hm} 19$ &  & $\mathrm{H} 1262 \times \mathrm{H} 752$ \\
\hline $\mathrm{Hm} 47$ & a gcn2::LEU2 gcd10-504 ura3-52 & $\mathrm{Hm} 19 \times \mathrm{H} 752$ \\
\hline $\mathrm{Hm} 44$ & a gcn $2:: L E U 2$ ura $3-52$ & $\mathrm{Hml9} \times \mathrm{H} 752$ \\
\hline $\mathrm{Hm} 203$ & $\alpha$ gcn3::LEU2 gcd10-504 ura3-52 & $\mathrm{Hm} 47 \times \mathrm{H} 742$ \\
\hline $\mathrm{Hm} 270$ & a gcn2::LEU2 GCD10::URA3 ura3-52 & $\mathrm{HM} 47 / \mathrm{pI} 105$ \\
\hline $\operatorname{Hm} 298$ & a gcn2-101 gcn3-101 gcd10-505 his1-29 ura3-52 [HIS4::lacZ, ura3-52] & $\mathrm{H} 174 \times \mathrm{H} 96$ \\
\hline MGYl & a/a gcn2::LEU2/gcn2::LEU2 GCD10/gcd10-504 ura3-52/ura3-52 & $\mathrm{Hm} 44 \times \mathrm{Hm} 47$ \\
\hline MGY2 & a/a trp1-63/trp1-63 ura3-52/ura3-52 leu2-3/leu2-3 leu2-112/leu2-112 & $\mathrm{H} 1514 \times \mathrm{H} 1515$ \\
\hline MGY3 & a top2-1 GCD10::URA3 ade2 ura3 his3-11 trp1-1 leu2-3 leu2-112 & $\mathrm{RS} 191 \times \mathrm{Hm} 270$ \\
\hline RS191 & a top2-1 ade2 ura3-1 his3-11 trp1-1 leu2-3 leu2-112 & $\begin{array}{l}\text { R. Sternglanz (State University } \\
\text { of New York, Stony Brook) }\end{array}$ \\
\hline F205 & $\alpha$ ras2-699 (HIS3 insertion) leu2-3 leu2-112 ura3-1 can1-100 ade2-1 his3 & $\begin{array}{l}\text { K. Tatchell (North Carolina } \\
\text { State University, Raleigh) }\end{array}$ \\
\hline W303 & a leu2-3, his3-11, ade2-1, trp1-1, can1-100 & Naranda et al. (1994) \\
\hline
\end{tabular}

The presence of these mutations is uncertain.

(Christianson et al. 1992) digested with ClaI and Xhol, after making the $X b a I$ and $C l a I$ sites blunt ended.

pMG107- $\Delta \mathrm{N}$ was constructed as follows. pMG80, containing the 3.45-kb HindIII fragment from pMGl05 (Fig. 1) inserted in the HindIII site of the SK + polylinker of Bluescript $\mathrm{Ml3}+$ (Stratagene), was digested with $\mathrm{NcoI}$ and SalI /the latter site is in the SK + polylinker), blunt-ended, and religated to generate p101. The deleted version of GCD10 in p101 was recovered by digestion with $X b a I$ and $X h o I$ (the latter site is present in the $\mathrm{SK}+$ polylinker) and inserted between the $\mathrm{XbaI}$ and $\mathrm{XhoI}$ sites of pRS316, generating pMG107- $\mathrm{N}$. pMG107-FSB was constructed by digesting pMG107 with BamHI and filling in the single site $5^{\prime}$ to GCD10 with Klenow enzyme, followed by religation. The insertion of the $4 \mathrm{bp}$ was verified by sequencing.

Plasmids pMG85 to pMG88 were generated as follows. The two fragments generated by digesting the $3.45-\mathrm{kb}$ HindIII fragment from pMG105 with BamHI were subcloned separately between the BamHI and HindIII sites in the polylinkers of Bluescript M13 + vectors. pMG85 and pMG86 (the latter contains the fragment with the ClaI site; Fig. 1) are the plasmids generated by subcloning the fragments in the $\mathrm{KS}+$ polylinker. pMG87 (containing the ClaI site) and pMG88 are the plasmids generated by subcloning the fragments in the $\mathrm{SK}+$ polylinker.

pMG108 was constructed by deleting an internal 451-bp fragment from the GCD10-coding region in pMG107 by digestion with ClaI and SpeI, and replacing it with a 1372-bp ClaI-NheI fragment from YEp24 (Parent et al. 1985) containing the URA3 gene. The ClaI-HindIII fragment comprising 247 codons of GCD10 was fused in-frame to the $\operatorname{trpE} E$-coding sequence in pATH1 (Dieckmann and Tzagoloff 1985) to generate pTRPC10.
Construction of the correct in-frame fusion was confirmed by DNA sequencing.

pMG 120 construct was produced as follows. The BamHI site in the pRS314 polylinker (Sikorski and Hieter 1989) was eliminated by digestion with $B a m H I$ followed by end-filling with Klenow and religation, generating pMG118. The GAL1-GAL1O promoter region present in plasmid pMB150 (Johnston 1987) was isolated by digestion with Sall and EcoRI and introduced into the pMG118 polylinker digested with the same enzymes, to generate pMGl19. Insertion of the BamHI-Xhol fragment from pMG107 containing the complete GCD10 ORF between the BamHI and SalI sites of pMG119 GAL1 promoter, produced pMG120.

\section{GCD10 disruption}

The method of Rothstein (1983) was used to replace wild-type GCD10 with the deletion/insertion allele shown in Figure 1. The $\sim 4.0-\mathrm{kb} \mathrm{XbaI-Xhol} \mathrm{fragment} \mathrm{from} \mathrm{pMG108} \mathrm{containing} \mathrm{the}$ gcd10A::URA3 allele was used to transform diploid strains MGY1 and MGY2. Replacement of GCD10 with the deletion allele on one homolog was verified by DNA blot-hybridization analysis of total DNA isolated from the $\mathrm{Ura}^{+}$transformants and digested with SpeI. The 1340-bp EcoRI fragment from the GCD10 ORF was radiolabeled and used as the probe in these experiments. As predicted, the probe detected only the $\sim 3-\mathrm{kb}$ fragment corresponding to the nondisrupted GCD10 allele in the untransformed diploid parent, whereas an additional $\sim 18$ $\mathrm{kb}$ fragment was detected in the transformed diploid strains.

To demonstrate that $g c d 10 \Delta:: U R A 3$ does not disrupt an ad- 
jacent gene, the $\mathrm{Ura}^{+}$transformants of diploids MGY1 and MGY2 that are heterozygous for $\operatorname{gcd} 10 \Delta:: U R A 3$ were transformed to $\operatorname{Trp}^{+}$with pMG120, sporulated and subjected to tetrad analysis. Tetrads with two, three, and four viable spores were obtained and phenotypic analysis showed that two of the four spores in the complete tetrads, and one of the spores in the three-spored tetrads were $\mathrm{Ura}^{+}$(and thus contained gcd10D::URA3). All such $\mathrm{Ura}^{+}$spores were $\operatorname{Trp}^{+}$, whereas half $(16 / 33)$ of the $\mathrm{Ura}^{-}$spores were $\mathrm{Trp}^{-}$. It is interesting that the pMG120 construct complements the lethality of gcd10D::URA3 even when glucose is the carbon source and the GAL1 promoter is expected to be repressed (data not shown).

\section{DNA sequence analysis}

Plasmids pMG85-pMG88 were used to generate a series of unidirectional nested deletions by the Exo III method of Henikoff (1987). The deletion subclones were classified by size and selected clones harboring inserts that were progressively reduced in size by $\sim 250$-bp increments were used to generate singlestranded DNA in E. coli MV1 190 and sequenced using a Sequenase version 2.0 kit (U.S. Biochemical Corp.). Regions beyond the HindIII sites, the region around $B a m H I$ and certain regions missing in the deletion clones were sequenced using oligonucleotides derived from the previously determined sequences as primers, with either pMG107 or pMGl01 serving as doublestranded DNA templates. The DNA sequence of $2681 \mathrm{bp}$ in the GCD10 region was determined and deposited in GenBank (accession no. X83511). Computer analysis of DNA sequences used the FASTA software of Pearson and Lipman (1988) and the Genetics Computer Group sequence analysis software package (Devereux et al. 1984).

\section{Chromosomal mapping of GCD10}

A set of filters containing an ordered $\lambda$ library of yeast genomic DNA fragments obtained from Dr. Linda Riles and Dr. Maynard Olson at Washington University (St. Louis, Mo; Riles et al. 1993), was probed with the 3.45-kb HindIII fragment from pMG105 radiolabeled by nick translation (Maniatis et al. 1982), following a protocol provided by L. Riles and M. Olson (pers. comm.) The GCD10 probe hybridized to clones 2784 and 1775 , localizing GCD10 to the left arm of chromosome XIV in a region between RAS2/TOP2 and the centromere. To map GCD10 more precisely, we crossed strain MGY3 (mata top2-1 GCD10::URA3 ade2 ura3 his3-11 trp1-1 leu2-3 leu2-112), bearing the Tsm ${ }^{-}$allele top2-1 and a URA3 allele of GCD10 with strain F205 (MAT $\alpha$ ras2-699 (HIS3 insertion) leu2-3 leu2-112 ura3-1 can 1-100 ade2-1 his3) containing a RAS2 allele marked with HIS3. Analysis of cosegregation for the Tsm, Ura, and His phenotypes in 145 tetrads gave the following results. For TOP2 and GCD10, we observed $101 \mathrm{PD}, 1 \mathrm{NPD}$, and $43 \mathrm{TT}$ asci; for RAS2 and GCD10, we observed $102 \mathrm{PD}, 0 \mathrm{NPD}$, and $43 \mathrm{TT}$ asci; for RAS2 and TOP2, we observed $130 \mathrm{PD}, 0 \mathrm{NPD}$, and 15 TT asci.. These results placed GCD10 $16.9 \mathrm{cM}$ from TOP2 and 14.82 cM from RAS2 (Breviario et al. 1986). In our crosses, RAS2 and TOP2 were separated by $5.17 \mathrm{cM}$, half the distance indicated in the last genetic and physical map of $S$. cerevisiae (Mortimer et al. 1989).

\section{Production and affinity purification of GCD10-specific antiserum}

The TrpE-GCD10 fusion protein encoded by pTRPC10 was overexpressed in $E$. coli strain $\mathrm{HB} 101$ and purified partially from the insoluble fraction of whole cell extracts by SDS-PAGE as already described (Dieckmann and Tzagoloff 1985). Gel slices containing $\sim 200 \mu \mathrm{g}$ of fusion protein were used to inoculate each rabbit. Immunization of the rabbits and collection of the antisera was conducted by Hazelton Laboratories (Vienna, VA). Antibodies specific for GCD10 were affinity purified by a modification of the protocol of Harlow and Lane (1988). Briefly, 1200 $\mu \mathrm{g}$ of the same $E$. coli extracts used to isolate the fusion protein for immunizations were fractionated by $10 \%$ SDS-PAGE and transferred to Immobilon-P (Millipore). Strips containing the fusion protein were blocked in $5 \%$ Blotto for $1 \mathrm{hr}$ and then incubated for 3-5 hr with $500 \mu \mathrm{l}$ of GCD10-specific antiserum diluted $1: 1$ in $5 \%$ Blotto. The strips were washed once in $5 \%$ Blotto and twice in TBS-T (ECL-Amersham). Antibodies were eluted from the strips by incubation for $20 \mathrm{~min}$ in $250 \mu \mathrm{l}$ of 100 mM glycine ( $\mathrm{pH} 2.5)$, followed by neutralization with $1 \mathrm{M}$ Tris$\mathrm{HCl}(\mathrm{pH} 8.0)$ and addition of BSA to $1 \%$.

\section{SDS-PAGE and immunoblotting techniques}

Immunoblot analysis of eIF-3 and GCD10 in the experiments shown in Figures 6 and 7 was carried out as follows. After SDSPAGE (Laemmli 1970), proteins were transferred to Immobilon PVDF membrane (Millipore) using a 10-mM CAPS [3-(cyclohexylamino/-1-propanesulfonic acid] $(\mathrm{pH} 11)$ buffer containing $10 \%$ (vol/vol) methanol. The membrane was blocked in Blotto $10.5 \%$ (wt/vol) nonfat dry milk in TST [10 mM Tris- $\mathrm{HCl}$ (pH 7.4), 150 $\mathrm{mM} \mathrm{NaCl}, 0.075 \%$ (vol/vol) Tween 20l, and probed with a 1 : 1000 dilution of rabbit polyclonal antiserum directed against eIF-3 (Naranda et al. 1994), or with 1:100 dilution of the affinitypurified anti-GCD10 antibody. Immune complexes were visualized as described previously (Naranda et al. 1994).

\section{RNA-binding (Northwestern) analysis}

Aliquots of $\sim 20 \mu \mathrm{g}$ of whole cell extracts from transformants of strain $\mathrm{H} 1642$ containing the high copy-number GCD10 plasmid pE107 or the vector pRS426 and equal volumes of Mono-S fractions ( $\leqslant 150 \mathrm{ng}$ of protein) were separated by $9 \%$ SDS-PAGE and transferred to a $0.45-\mu \mathrm{m}$ nitrocellulose membrane (Schleicher \& Schuell) in $10 \mathrm{~mm}$ CAPS (pH 11), 10\% (vol/vol) methanol buffer. A 354-nucleotide BamHI runoff transcript from pSP64-x $\beta \mathrm{m}$ (Krieg and Melton 1984) encoding Xenopus $\beta$-globin was prepared. The blot was probed with this radiolabeled transcript and developed as described previously (Naranda et al. 1994). After autoradiography to identify RNA-binding polypeptides, the blot was processed for immunodetection using anti-GCD10 antibodies. In the studies performed with pure factors, $500 \mathrm{ng}$ of $\mathrm{HeLa}$, yeast or reticulocyte eIF-3 was resolved by $8 \%$ SDS-PAGE and analyzed as just described.

\section{Analysis of polysome profiles}

For the experiment shown in Figure 4, strains $\mathrm{H} 117$ and $\mathrm{H} 255$ were cultured overnight in YEPD at $23^{\circ} \mathrm{C}$ (room temperature) and used to inoculate four flasks (A, B, C, and D) containing 400 $\mathrm{ml}$ of YEPD to an $\mathrm{OD}_{600}$ of $\sim 0.1$. Cultures were incubated at room temperature in a rotary shaker at $250 \mathrm{rpm}$. At $\mathrm{OD}_{600} \cong 5.0$, $175 \mathrm{ml}$ was collected from flasks $A$ and $C$ for the $t=0$ samples at room temperature. Cycloheximide was added to the remaining culture in flask A at $50 \mu \mathrm{g} / \mathrm{ml}$. Simultaneously, the cultures in flasks B and D were centrifuged at room temperature for 10 min at $4000 \mathrm{rpm}$ and resuspended in $400 \mathrm{ml}$ of YEPD prewarmed to $39^{\circ} \mathrm{C}$. From flasks B and D $175 \mathrm{ml}$ was collected immediately for the $t=0$ points at $39^{\circ} \mathrm{C}$. [The polysome profiles were identical for the $t=0$ samples at $23^{\circ} \mathrm{C}$ and $39^{\circ} \mathrm{C}$, indicating that the centrifugation at room temperature did not affect the 
results (data not shown)]. Concurrent with the temperature shift, cycloheximide was added to flask B. After removal of the $175-\mathrm{ml}$ samples from flasks $\mathrm{C}$ and $\mathrm{D}$ described above, $175 \mathrm{ml}$ of fresh prewarmed YEPD was added back to each flask. Samples of $200 \mathrm{ml}$ were collected from flasks C and D at 1.5-hr intervals. Cultures were maintained in logarithmic growth phase throughout the experiment by collecting half the volume of the culture at each time point and diluting the remaining half with an equal volume of prewarmed YEPD. Samples from the control flasks containing cycloheximide were taken only at $t=0$ and $t=4.5 \mathrm{hr}$. Whole cell extracts were prepared and fractionated on linear $7 \%-47 \%$ low-salt sucrose gradients exactly as described previously (Foiani et al. 1991).

Fractionation of polysomes in the prt1-1 strain F294 shown in Figure $5 \mathrm{~A}$ and immunoblot analysis of the gradient fractions were carried out as described previously (Foiani et al. 1991), except that total proteins in each fraction were TCA precipitated and loaded on the gel, and immunodetection was carried using the ECL kit from Amersham.

\section{Purification of the eIF-3 complex}

The yeast eIF-3 complex was purified from strain W303 as described previously (Naranda et al. 1994). Briefly, cells were grown to $\mathrm{OD}_{600}=1.75$, digested with lyticase and homogenized on ice with a Dounce homogenizer, and a ribosomal pellet was prepared from the $S 30$ fraction by centrifugation at $46,000 \mathrm{rpm}$. The ribosomal HSW enriched in initiation factors was prepared and fractionated on a Superose- 6 gel filtration column using the fast protein liquid chromatography system (FPLC) of Pharmacia LKB Biotechnology, Inc. The presence of eIF-3 in column fractions was determined by the Met-PM synthesis assay and by immunoblot analysis, as described below. Fractions containing the eIF-3 complex that correspond to a molecular mass of 550 $\mathrm{kD}$ were applied to a Mono-S $5 / 5$ column (FPLC, Pharmacia LKB Biotechnology Inc.) and eluted with a linear 100-450 mM $\mathrm{KCl}$ gradient. The eIF-3 activity in the fractions, which eluted at $\sim 0.2 \mathrm{M} \mathrm{KCl}$, was determined by the Met-PM assay.

\section{Met-PM synthesis assay}

Yeast eIF-3 (YeIF-3) was detected by its ability to substitute for HeLa eIF-3 in stimulating Met-PM synthesis (Naranda et al. 1994 ) in assays containing either $2.0 \mu \mathrm{g}$ of purified YeIF-3, or the fractions being tested, and the following amounts of purified HeLa factors: $0.9 \mu \mathrm{g}$ of eIF-2, $0.6 \mu \mathrm{g}$ of eIF-5, $0.27 \mu \mathrm{g}$ of eIF-1 A, $0.96 \mu \mathrm{g}$ of eIF-5A. Reaction mixtures of $30 \mu \mathrm{l}$ also contained 20 $\mathrm{mM}$ Tris- $\mathrm{HCl}(\mathrm{pH} 7.6), 2 \mathrm{~mm} \mathrm{Mg}(\mathrm{OAc})_{2}, 70 \mathrm{~mm} \mathrm{KCl}, 10 \mathrm{~mm}$ $\beta$-mercaptoethanol, 1.6 pmoles of $\left[{ }^{3} \mathrm{H}\right]$ methionyl-tRNA /sp. act. $2.1 \times 10^{3} \mathrm{cpm} /$ pmole), $0.8 \mathrm{~mm}$ GTP, $1 \mathrm{~mm}$ puromycin, $33 \mathrm{~mm}$ $\mathrm{ApUpG}, 0.06$, and $0.15 A_{260}$ units of $40 \mathrm{~S}$ and $60 \mathrm{~S}$ rat liver ribosomal subunits, respectively. The reaction mixtures were incubated at $37^{\circ} \mathrm{C}$ for $20 \mathrm{~min}$, diluted with $0.2 \mathrm{M}$ phosphate buffer (pH 8.0), extracted with ethyl acetate, and an aliquot of the organic phase was counted by liquid scintillation.

\section{Coimmunoprecipitations}

Antibodies were cross-linked to GammaBind-G Sepharose beads (Pharmacia) using the bifunctional coupling reagent dimethylpimelimidate (Harlow and Lane 1988). Approximately 2 mg of antiserum was bound per milliter of beads, except GCD10 antiserum, for which twice this amount was used. After coupling to antibodies, beads were equilibrated in buffer A $[30 \mathrm{mM}$ HEPES ( $\mathrm{pH} 8.0$ ), $100 \mathrm{~mm}$ potassium acetate, $3 \mathrm{~mm}$ magnesium acetate, $1 \mathrm{~mm}$ dithiothreitol, $0.1 \%$ SDS, $1 \%$ NP-40, $1 \mathrm{~mm}$
AEBSF (Calbiotech)]. Samples containing $50 \mu \mathrm{g}$ of HSW prepared as already described (Naranda et al. 1994) or $\sim 4 \mu \mathrm{g}$ from the Mono-S fractions containing the peak of eIF-3 activity were adjusted to $100 \mathrm{~mm}$ potassium acetate with buffer $\mathrm{A}$ in a final volume of $100 \mu \mathrm{l}$ and incubated for $30 \mathrm{~min}$ at $25^{\circ} \mathrm{C}$ with $25 \mu \mathrm{l}$ of a 1:1 slurry of GammaBind-G Sepharose beads in buffer A. The beads were collected by brief centrifugation and discarded to remove antigens that bound nonspecifically to G Sepharose. The remaining supernatants were mixed with $30 \mu$ l of beads containing cross-linked antibodies and incubated for 3-5 hr at $4^{\circ} \mathrm{C}$ on a rotating mixer. Samples were centrifuged briefly and the supernatants removed. The beads were washed with $400 \mu \mathrm{l}$ of buffer A four times, and once with $400 \mu \mathrm{l}$ of $63 \mathrm{~mm}$ Tris- $\mathrm{HCl}$ (pH 6.8). The washed beads were incubated with $50 \mu$ l of Laemmli sample buffer (Laemmli 1970), and heated at $90^{\circ} \mathrm{C}$ for $3 \mathrm{~min}$, and the supernatants were analyzed by SDS-PAGE and immunoblotted as described above. In our initial experiments, equivalent proportions of supernatants and pellet fractions were analyzed to determine the fraction of the proteins that were recovered in immune complexes.

\section{Acknowledgments}

We are grateful to Susan MacMillan for technical assistance, to Thomas Dever for the purified rabbit eIF-3, to Graham Pavitt and Thomas Dever for helpful comments on the manuscript, to Lon Phan for pointing out the RRM-like motif in GCD10, and to Kelly Tatchell and Rolf Sternglanz for gifts of strains. The work was supported in part by grant GM22135 from the U.S.Public Health Service to J.W.B.H., and by grants Bio526/89 from the Comision Interministerial de Ciencia y Tecnologia, Spain and CRG 920605 from NATO to M.T. M.T.G. was supported by a fellowship from the Ministerio de Educacion y Ciencia (M.E.C.) of Spain in the program Quinto Centenario.

The publication costs of this article were defrayed in part by payment of page charges. This article must therefore be hereby marked "advertisement" in accordance with 18 USC section 1734 solely to indicate this fact.

\section{References}

Abastado, J.P., P.F. Miller, B.M. Jackson, and A.G. Hinnebusch. 1991. Suppression of ribosomal reinitiation at upstream open reading frames in amino acid-starved cells forms the basis for GCN4 translational control. Mol. Cell. Biol. 11: 486-496.

Benne, R. and J.W.B. Hershey. 1978. The mechanism of action of protein synthesis initiation factors from rabbit reticulocytes. I. Biol. Chem. 253: 3078-3087.

Birney, E., S. Kumar, and A.R. Krainer. 1993. Analysis of the RNA-recognition motif and RS and RGG domains: Conservation in metazoan pre-mRNA splicing factors. Nucleic Acids Res. 21: 803-5816.

Breviario, D., A. Hinnebusch, J. Cannon, K. Tatchell, and R. Dhar. 1986. Carbon source regulation of RAS1 expression in Saccharomyces cerevisiae and the phenotypes of ras2- cells. Proc. Natl. Acad. Sci. 83: 4152-4156.

Chia-Lin, W., S.E. MacMillan, and J.W.B. Hershey. 1995. Protein synthesis initiation factor eIF-1A is a moderately abundant RNA-binding protein. J. Biol. Chem. 270: 5764-5771.

Christianson, T.W., R.S. Sikorski, M. Dante, and P. Hieter. 1992. Multifunctional yeast high-copy-number shuttle vectors. Gene 110: 119-122.

Cigan, A.M., M. Foiani, E.M. Hannig, and A.G. Hinnebusch. 1991. Complex formation by positive and negative transla- 
tional regulators of GCN4. Mol. Cell. Biol. 11: 3217-3228. Cigan, A.M., J.L. Bushman, T.R. Boal, and A.G. Hinnebusch. 1993. A protein complex of translational regulators of GCN4 is the guanine nucleotide exchange factor for eIF-2 in yeast. Proc. Natl. Acad. Sci. 90: 5350-5354.

Danaie, P., B. Wittmer, M. Altmann, and H. Trachsel. 1995. Isolation of a protein complex containing translation initiation factor Prtl from Saccharomyces cerevisiae. /. Biol. Chem. 270: 4288-4292.

de Beus, F., J.S. Brockenbrough, B. Hong, and J.P. Aris. 1994. Yeast NOP2 encodes an essential nucleolar protein with homology to human proliferation marker. I. Cell. Biol. 127: 1799-1813.

Devenish, R. and C. Newlon. 1982. Isolation and characterization of yeast ring chromosome III by a method applicable to other circular DNAs. Gene 18: 277-288.

Dever, T.E., L. Feng, R.C. Wek, A.M. Cigan, T.D. Donahue, and A.G. Hinnebusch. 1992. Phosphorylation of initiation factor $2 \alpha$ by protein kinase GCN2 mediates gene-specific translational control of GCN4 in yeast. Cell 68: 585-596.

Dever, T.E., J-J. Chen, G.N. Barber, A.M. Cigan, L. Feng, T.F. Donahue, I.M. London, M.G. Katze, and A.G. Hinnebusch. 1993. Mammalian eukaryotic initiation factor $2 \alpha$ kinases functionally substitute for GCN2 in the GCN4 translational control mechanism of yeast. Proc. Natl. Acad. Sci. 90: 46164620.

Devereux, J., P. Haeberli, and O. Smithies. 1984. A comprehensive set of sequence analysis programs for the VAX. Nucleic Acids Res. 12: 387-395.

Dieckmann, C.L. and A. Tzagoloff. 1985. Assembly of the mitochondrial membrane system. I. Biol. Chem. 260: 15131520.

Feinberg, B., C.S. McLaughlin, and K. Moldave. 1982. Analysis of temperature-sensitive mutant ts 187 of Saccharomyces cerevisiae altered in a component required for the initiation of protein synthesis. J. Biol. Chem. 257: 10846-10851.

Foiani, M., A.M. Cigan, C.J. Paddon, S. Harashima, and A.G. Hinnebusch. 1991. GCD2, a translational repressor of the GCN4 gene, has a general function in the initiation of protein synthesis in Saccharomyces cerevisiae. Mol. Cell. Biol. 11: 3203-3216.

Hannig, E.M., A.M. Cigan, B.A. Freeman, and T.G. Kinzy. 1992. GCD11, a negative regulator of GCN4 expression, encodes the gamma subunit of eIF-2 in Saccharomyces cerevisiae. Mol. Cell. Biol. 13: 506-520.

Harashima, S. and A.G. Hinnebusch. 1986. Multiple GCD genes required for repression of GCN4, a transcriptional activator of amino acid biosynthetic genes in Saccharomyces cerevisiae. Mol. Cell. Biol. 6: 3990-3998.

Harlow, E. and D. Lane. 1988. Immunoaffinity purification. In Antibodies: A laboratory manual, pp. 283-523. Cold Spring Harbor Laboratory, Cold Spring Harbor, New York.

Henikoff, S. 1987. Unidirectional digestion with exonuclease III in DNA sequence analysis. Methods Enzymol. 155: 156165.

Hershey, J.W.B. 1991. Translational control in mammalian cells. Annu. Rev. Biochem. 60: 717-755.

Hinnebusch, A.G. 1992. General and pathway-specific regulatory mechanisms controlling the synthesis of amino acid biosynthetic enzymes in Saccharomyces cerevisiae. In The molecular and cellular biology of the yeast Saccharomyces: Gene expression (ed. E.W. Jones, J.R. Pringle, and J.R. Broach), pp. 319-414. Cold Spring Harbor Laboratory Press, Cold Spring Harbor, New York.

- 1994. Translational control of GCN4: An in vivo barometer of initiation factor activity. Trends Biochem. Sci.
19: 409-414.

Hinnebusch, A.G., and G.R. Fink. 1983a. Positive regulation in the general amino acid control of Saccharomyces cerevisiae. Proc. Natl. Acad. Sci. 80: 5374-5378.

- 1983b. Repeated DNA sequences upstream from HIS1 also occur at several other co-regulated genes in Saccharomyces cerevisiae. I. Biol. Chem. 258: 5238-5247.

Ito, H., Y. Fukada, K. Murata, and A. Kimura. 1983. Transformation of intact yeast cells treated with alkali cations. $J$. Bacteriol. 153: 163-168.

Johnston, M. 1987. A model fungal gene regulatory mechanism: The GAL genes of Saccharomyces cerevisiae. Microb. Rev. 51: 458-476.

Krieg, P.A. and D.A. Melton. 1984. Functional messenger RNAs are produced by SP6 in vitro transcription of cloned cDNAs. Nucleic Acids Res. 12: 7057-7070.

Laemmli, U. 1970. Cleavage of structural proteins during the assembly of the head of bacteriophage T4. Nature 227: 680685.

Lanker, S., J.L. Bushman, A.G. Hinnebusch, H. Trachsel, and P.P. Mueller. 1992. Autoregulation of the yeast lysyl-tRNA synthetase gene GCD5/KRS1 by translational and transcriptional control mechanisms. Cell 70: 647-657.

Maniatis, T., E.F. Fritsch, and J. Sambrook. 1982. Molecular cloning: A laboratory manual. Cold Spring Harbor Laboratory, Cold Spring Harbor, New York.

Mortimer, R.K., D. Schild, C.R. Contopoulou, and J.A. Kans. 1989. Genetic map of Saccharomyces cerevisiae, 10th ed. Yeast 5: 328-331.

Mueller, P.P., S. Harashima, and A.G. Hinnebusch. 1987. A segment of GCN4 mRNA containing the upstream AUG codons confers translational control upon a heterologous yeast transcript. Proc. Natl. Acad. Sci. 84: 2863-2867.

Naranda, T., S.E. MacMillan, and J.W.B. Hershey. 1994. Purified yeast translational initiation factor eIF-3 is an RNA-binding protein complex that contains the PRT1 protein. $/$. Biol. Chem. 269: 32286-32292.

Nygard, O. and P. Westermann. 1982. Specific interaction of one subunit of eukaryotic initiation factor eIF-3 with 18S rRNA within the binary complex, eIF-3.small ribosomal subunit, as shown by cross-linking experiments. Nucleic Acids Res. 10: $1327-1334$.

Parent, S.A., C.M. Fenimore, and K.A. Bostian. 1985. Vector systems for the expression, analysis and cloning of DNA sequences in S. cerevisiae. Yeast 1: 83-138.

Pearson, W.R. and D. Lipman. 1988. Improved tools for biological sequence comparison. Proc. Natl. Acad. Sci. 85: 2444 2448.

Query, C.C., R.C. Bentley, and J.D. Keene. 1989. A common RNA recognition motif identified within a defined U1 RNA binding domain of the 70K U1 snRNP protein. Cell 57: 89101.

Ramirez, M., R.C. Wek, and A.G. Hinnebusch. 1991. Ribosomeassociation of GCN2 protein kinase, a translational activator of the GCN4 gene of Saccharomyces cerevisae. Mol. Cell. Biol. 11: 3027-3036.

Riles, L., J.E. Dutchik, A. Baktha, B.K. McCauley, E.C. Thayer, M.P. Leckie, V.V. Braden, J.E. Depke, and M.V. Olson. 1993. Physical maps of the six smallest chromosomes of Saccharomyces cerevisiae. Genetics 134: 81-150.

Rolfes, R.J. and A.G. Hinnebusch. 1993. Translation of the yeast transcriptional activator GCN4 is stimulated by purine limitation: Implications for activation of the protein kinase GCN2. Mol. Cell. Biol. 13: 5099-5111.

Romano, P.R., S.R. Green, G.N. Barber, M.B. Mathews, and A.G. Hinnebusch. 1995. Structural requirements for double- 


\section{Garcia-Barrio et al.}

stranded RNA binding, dimerization, and activation of the human eIF- $2 \alpha$ kinase DAI in Saccharomyces cerevisiae. Mol. Cell. Biol. 15: 365-378.

Rose, M., P. Novick, J. Thomas, D. Botstein, and G.R. Fink. 1987. A Saccharomyces cerevisiae plasmid bank based on a centromere-containing shuttle vector. Gene 60: 237-243.

Rothstein, R.J. 1983. One-step gene disruption in yeast. Methods Enzymol. 101: 202-211.

Sambrook, J., E.F. Fritsch, and T. Maniatis. 1989. Molecular cloning: A laboratory manual. Cold Spring Harbor Laboratory Press, Cold Spring Harbor, New York.

Sherman, F., G.R. Fink, and C.W. Lawrence. 1974. Methods in yeast genetics. Cold Spring Harbor Laboratory, Cold Spring Harbor, New York.

Sikorski, R.S. and P. Hieter. 1989. A system of shuttle vectors and yeast host strains designated for efficient manipulation of DNA in Saccharomyces cerevisiae. Genetics 122: 19-27.

Struhl, K., D.T. Stinchomb, S. Scherer, and R.W. Davis. 1979. High frequency transformation of yeast: Autonomous replication of hybrid DNA molecules. Proc. Natl. Acad. Sci. 76: 1035-1039.

Trachsel, H. and T. Staehelin. 1979. Initiation of mammalian protein synthesis: The multiple functions of the initiation factor eIF-3. Biochim. Biophys. Acta 565: 305-314.

Vazquez de Aldana, C.R. and A.G. Hinnebusch. 1994. Mutations in the GCD7 subunit of yeast guanine nucleotide exchange factor eIF-2B overcome the inhibitory effects of phosphorylated eIF-2 on translation initiation. Mol. Cell. Biol. 14: 3208-3222.

Vazquez de Aldana, C.R., T.E. Dever, and A.G. Hinnebusch. 1993. Mutations in the $\alpha$ subunit of eukaryotic translation initiation factor 2 (eIF- $2 \alpha$ ) that overcome the inhibitory effects of elF- $2 \alpha$ phosphorylation on translation initiation. Proc. Natl. Acad. Sci. 90: 7215-7219.

Westermann, P. and O. Nygard. 1984. Cross-linking of mRNA to initiation factor eIF-3, $24 \mathrm{kDa}$ cap binding protein and ribosomal proteins $\mathrm{S} 1, \mathrm{~S} 3 / 3 \mathrm{a}, \mathrm{S} 6$ and $\mathrm{S} 11$ within the $48 \mathrm{~S}$ pre-initiation complex. Nucleic Acids Res. 12: 8887-8897. 




\section{GCD10, a translational repressor of GCN4, is the RNA-binding subunit of eukaryotic translation initiation factor-3.}

M T Garcia-Barrio, T Naranda, C R Vazquez de Aldana, et al.

Genes Dev. 1995, 9:

Access the most recent version at doi:10.1101/gad.9.14.1781

References This article cites 48 articles, 28 of which can be accessed free at:

http://genesdev.cshlp.org/content/9/14/1781.full.html\#ref-list-1

License

Email Alerting

Service

Receive free email alerts when new articles cite this article - sign up in the box at the top right corner of the article or click here.

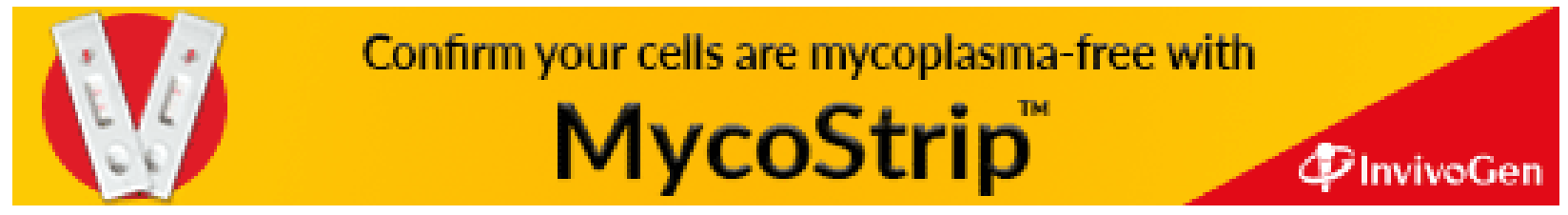

